\title{
Global scaling of the heat transport in fusion plasmas
}

\author{
Sara Moradi $\mathbb{B}^{*}$ \\ Laboratory for Plasma Physics, LPP-ERM/KMS, Royal Military Academy, 1000 Brussels, Belgium
}

Johan Anderson ${ }^{\dagger}$

Department of Space, Earth, and Environment, Chalmers University of Technology, SE-412 96 Göteborg, Sweden

Michele Romanelli

Culham Centre for Fusion Energy, Culham Science Centre, Abingdon, OX14 3DB, United Kingdom

Hyun-Tae Kim

EUROfusion Programme Management Unit, Culham Science Centre, Abingdon, OX14 3DB, United Kingdom

JET contributors $*$

EUROfusion Consortium, JET, Culham Science Centre, Abingdon, OX14 3DB, United Kingdom

(Received 4 July 2019; published 8 January 2020)

\begin{abstract}
A global heat flux model based on a fractional derivative of plasma pressure is proposed for the heat transport in fusion plasmas. The degree of the fractional derivative of the heat flux, $\alpha$, is defined through the power balance analysis of the steady state. The model was used to obtain the experimental values of $\alpha$ for a large database of the Joint European Torus (JET) carbon-wall as well as ITER like-wall plasmas. The fractional degrees of the electron heat flux are found to be $\alpha<2$, for all the selected pulses in the database, suggesting a deviation from the diffusive paradigm. Moreover, the results show that as the volume integrated input power is increased, the fractional degree of the electron heat flux converges to $\alpha \sim 0.8$, indicating a global scaling between the net heating and the pressure profile in the high-power JET plasmas. The model is expected to provide insight into the proper kinetic description for the fusion plasmas and improve the accuracy of the heat transport predictions.
\end{abstract}

DOI: 10.1103/PhysRevResearch.2.013027

\section{INTRODUCTION}

Fusion plasmas are open systems with continuous energy input, inherently having a continuous drive of turbulence at many scales, i.e., similar to or approaching a scale-free process, leading to a behavior that is much more complex than standard diffusion. It is now recognized that turbulenceinduced transport phenomena must be interpreted in the framework of the anomalous or turbulent diffusion as opposed to "normal" diffusion which is due to Brownian motion described by the Wiener process [1]. Anomalous transport is characterized by non-Gaussian (e.g., exhibiting a power-law tail) self-similar nature of the probability distribution function (PDFs) of particle displacement and the anomalous scaling of the moments [2-9].

\footnotetext{
*sara.moradi@ukaea.uk

†anderson.johan@gmail.com

Full author list given at the end of the article.
}

Published by the American Physical Society under the terms of the Creative Commons Attribution 4.0 International license. Further distribution of this work must maintain attribution to the author(s) and the published article's title, journal citation, and DOI.
Indeed, fluctuation measurements by Langmuir probes have provided abundant evidence to support the idea that density and potential fluctuations are distributed according to non-Gaussian PDFs and exhibit long-range correlations; see Refs. [10-22]. Recent analysis of fluctuation measurements from beam emission spectroscopy (BES) of mega ampere spherical tokamak (MAST) plasmas also shows evidence of skewed PDFs of density fluctuations in the near turbulence threshold regimes; see Ref. [23,24]. The skewed PDFs are suggested to be due to breaking of up-down and reflection symmetries of the fluctuation field by sheared flows [25]. Similar results were witnessed at the Large Plasma Device facility at UCLA [26], where vorticity probes (VP) were used to directly measurement the vorticity associated with $\mathbf{E} \times \mathbf{B}$ flow shear. These regimes possess complex dynamics and self-organization properties that display unimodal nonGaussian features, which is one of the signatures of intermittent turbulence with patchy spatial structure that is bursty in time [27-29]. Therefore, the statistical properties of such dynamical chaotic systems fall outside the domain of the diffusive paradigm described by Brownian motion.

Another school of thought based on fractional kinetics for systems with Hamiltonian chaos has gained momentum in different areas of applications, such as particle dynamics in different potentials, particle advection in fluids, plasma 
physics and fusion devices, quantum optics, and many others [30,31]. The characteristics of the kinetics are involved with fractional kinetics and the most important are anomalous transport, superdiffusion, and weak mixing. Fractional kinetics are tied closely to Lévy statistics, describing fractal processes (Lévy index $\alpha$ where $0<\alpha \leqslant 2$ ) [32]. Lévy statistics are considered to be at the heart of complex processes such as anomalous diffusion that can be generated by random processes that are scale invariant. From a physical point of view, these Lévy flights are the results of strong collisions between the particle and the surrounding environment, such as turbulence-driven flows. The scale-invariant and self-similar nature of Lévy stable distributions gives rise to the occurrence of large increments of the velocity and position coordinates during small time increments, violating the local character of the collision integrals in the traditional deterministic equations. Experimental observation of the intermittent particle flux at the edge of ADITYA tokamak has been reported in Refs. [33-35], where Lévy processes are thought to play key roles in the bursty fluctuations.

Even though the application of fractional kinetics in the study of turbulence phenomena shows great promise in resolving many open issues in the field, the current state of the art has not gone beyond phenomenological levels such as fractional Fokker-Plank equation (FFPE) [36,37] or Lévy random walk ideas [38]. An important reason for this is the lack of a connection between the dynamic of the system to that of the Lévy index $\alpha$. Clearly a dynamical system moving through different phases, e.g., laminar to transitional to fully developed turbulent flow, cannot be simply fixed by a given $\alpha$ a priori. Instead, it has to be linked to the underlying nonlinear dynamic of the system. A way to obtain the information regarding the value of $\alpha$ is to directly examine the experimental data.

In this work, we propose a global transport model based on a fractional approach. In this reduced model, the aim is to construct a transport model that can represent most plasmas with sufficiently high fidelity in terms of reproducing plasma profiles and significantly reduced computing resources. The main objective is to define the fractional index $\alpha$, of the heat flux in tokamak plasma experiments through a power balance analysis of the steady-state profiles over the whole plasma region. Here, the divergence of the heat flux is modeled by a fractional derivative of the plasma pressure. The model depends on a single fractional index $\alpha$ that describe the degree of the global heat transport; i.e., the flux of the transported scalar at a point depends on the gradient of the scalar throughout the entire domain. This leads to constant heat diffusion coefficient to the cost of a fractional power exponent $\alpha$ over the radial profile in contrast to current modeling efforts where sharp variation in heat diffusivity while using a regular model with $\alpha=2.0$ in each radial point is found. Analysis show that the experimental values of $\alpha$ for a large database of the JET carbon-wall as well as ITER like-wall plasmas is $<2$ with slightly lower values obtained for electrons than for ions. Here it is pertinent to keep in mind that the success of a fractional model indicates that there is a lack of physics in the current collisional and turbulent transport models which may be due to unphysical variations in the coefficient of heat diffusivity [39-45], namely the superdiffusive character of the heat transport. Note that although we have employed the methodology for heat flux in magnetically confined plasmas, it is a general methodology that could be applied in any instance where a fractional model of dynamics is used.

\section{THE GLOBAL TRANSPORT MODEL}

We start by examining the fluid equation for conservation of plasma energy in the following simplified form:

$$
\frac{3}{2} \frac{\partial}{\partial t} p_{j}(\mathbf{r}, t)+\nabla \cdot Q_{j}(\mathbf{r}, t)=H_{j}(\mathbf{r}, t),
$$

where $\mathbf{r}$ represents the cylindrical coordinate system $(R, Z, \phi)$ with $R$ being the radial position along the major radius, $Z$ being the vertical position, and $\phi$ being the toroidal angle. $Q_{j}$ describes the heat flux, $H_{j}$ is the net heating, and $p_{j}$ is the pressure. The parallel (to the magnetic field lines) heat transport in tokamaks is significantly higher than the perpendicular one, and we can assume equilibration in parallel direction. Here, therefore, we neglect the parallel heat flux and only consider the heat transport in $(R, Z)$ plain. In addition to Eq. (1), an equation for the evolution of the density profile is also needed; however, we have limited our analysis to the heat transport. Note that in principle a heat flux defined as (1) includes all the processes that contribute to the steady-state heat flux, i.e., magneto-hydro-dynamic (MHD), turbulence as well as the neoclassical processes. We now introduce a modified equation including the following general form for the divergence of the heat flux (see Ref. [46]),

$$
\nabla \cdot Q_{j}(\mathbf{r}, t)=D_{|\mathbf{r}|}^{\alpha_{j}} S_{j} p_{j}(\mathbf{r}, t),
$$

where $D_{|\mathbf{r}|}^{\alpha_{j}}$ is the fractional derivative operator with $\alpha_{j}$ as the index of the fractional derivative [46]. To ensure the correct dimensionality, we have introduced $S_{s}$ as an effective (i.e., constant) superdiffusive transport coefficient with the dimensionality of $\left[L^{\alpha_{j}} / s\right]$. For $\alpha_{j}=2$, we get a purely diffusive model, and for $\alpha_{j}=1$ we obtain a purely convective transport model where the flux is defined as $Q_{j}=S_{j} p_{j}$, and $S_{j}[L / T]$ becomes the heat convective velocity. For $\alpha<2$, therefore, the transport is so-called superdiffusive, and as $\alpha_{s}$ is lower the level of the superdiffusive transport is higher.

To define $\alpha_{j}$, we propose to make use of the Fourier representation of (1) as (see Ref. [46]):

$$
\frac{3}{2} \frac{\partial}{\partial t} \hat{p}_{j}(\mathbf{k}, t)-|\mathbf{k}|^{\alpha_{j}} \hat{p}_{j}(\mathbf{k}, t)=\hat{H}_{j}(\mathbf{k}, t) .
$$

Here, $\hat{X}$ represents the Fourier representation of quantity $X$ and $\mathbf{k}=\sqrt{k_{R}^{2}+k_{Z}^{2}}$, where $k=(2 \pi / L)[0 \ldots M / 2-10-$ $M / 2+1 \ldots-1]$ with $L=2 m$ in the radial direction and $L=4 m$ in the vertical direction. $M=256$ modes have been considered. For simplicity, we have assumed $S_{j}=1$. This means that all the physics contributing to the transport, namely collisional, neoclassical, and turbulence processes, is contained within the fractional index $\alpha_{j}$. Through a power balance analysis using Eq. (3), we can find the following expression for $\alpha_{j}$ :

$$
\alpha_{j}=\frac{\log \left(\frac{\hat{H}_{j}-(3 / 2) \partial_{t} \hat{p}_{j}}{-\hat{p}_{j}}\right)}{\log |\mathbf{k}|} .
$$




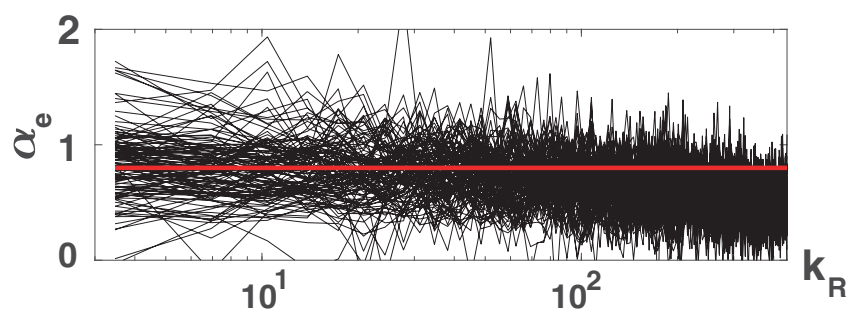

FIG. 1. The computed value of $\alpha_{e}$ for the plasma shot \#92071 as function of $k_{R}$ at various $k_{Z}$; the corresponding averaged value is $\alpha_{e}=0.8$ (red solid line). This discharge is an ELMy H-mode pulse of hybrid type from ILW with $30 \mathrm{MW}$ total input power (25 MW NBI $+6.6 \mathrm{MW}$ ICRH) and regular type I ELMs during the steady-state phase.

The fractional index, $\alpha_{j}$, as defined above, will be a complex number and a function of $\mathbf{k}$ [see, for example, the computed values of $\alpha\left(k_{R}, k_{Z}\right)$ in Fig. 1]. In the Fourier space, the imaginary part of each wave and the variations in $\mathbf{k}$ represent the detail structures in the profiles of heating and the pressure, e.g., an off- or on-axis heating schemes, or presence of edge-core transport barriers. The detail information encapsulated within the $\mathbf{k}$ dependence of $\alpha$ 's should in principle be included in the superdiffusive transport coefficient, $S$. Here we are interested in a fractional transport model with a constant fractional degree, and therefore, in order to define a scale-independent fractional index, we perform an averaging over the scales. Our choice is motivated by the assumption that an averaged $\alpha$ represents the dominant scale dependence, and it will be suitable as a first-order transport model. As can be seen in Fig. 1, for example, the $\mathbf{k}$ dependence in a high-power plasma (\#92071) from ITER Like Wall (ILW) with 30 MW total input power shows a dominant fractional exponent centered around the average of $\alpha_{e}=0.8$ (shown with solid red line). We note that by taking a constant $\alpha<2$ the dependence on different scales is closer to the experimental spectrum as compared to a regular diffusion model.

It is interesting to note the similarities of this scaling to the situation where fluid is forced on a certain scale, yielding a cascade (Kolmogorov) with well-defined properties for the other scales. This relation in $\alpha$ suggests that as the forcing (input power) increases as a sort of cascade up and down occurs, generating a well-defined fractional scaling $(\alpha)$. Further, the type of scaling or cascade found may be dependent on the forcing scale and several regions with different scalings in $\alpha$ may appear. Furthermore, with decreasing $\alpha$, the dampening of small-scale modes such as electron temperature gradient (ETG) modes will be less prominent, due to the reduced dissipation effect of the term $|\mathbf{k}|^{\alpha}$. Hence, such modes may be of enhanced importance in plasmas with a strong nondiffusive component.

For the steady state, the time-derivative term in the numerator vanishes, and the value of $\alpha$ depends on the ratio of the heating power to the pressure. In a sense, the single value of $\alpha$ obtained in this way gives the relation between the two profiles of pressure and the net heating deposition at the steady state. It represents the final relaxation state of the pressure profile due to the all of the different turbulent mechanisms and collisions that move the energy and particles in and out of
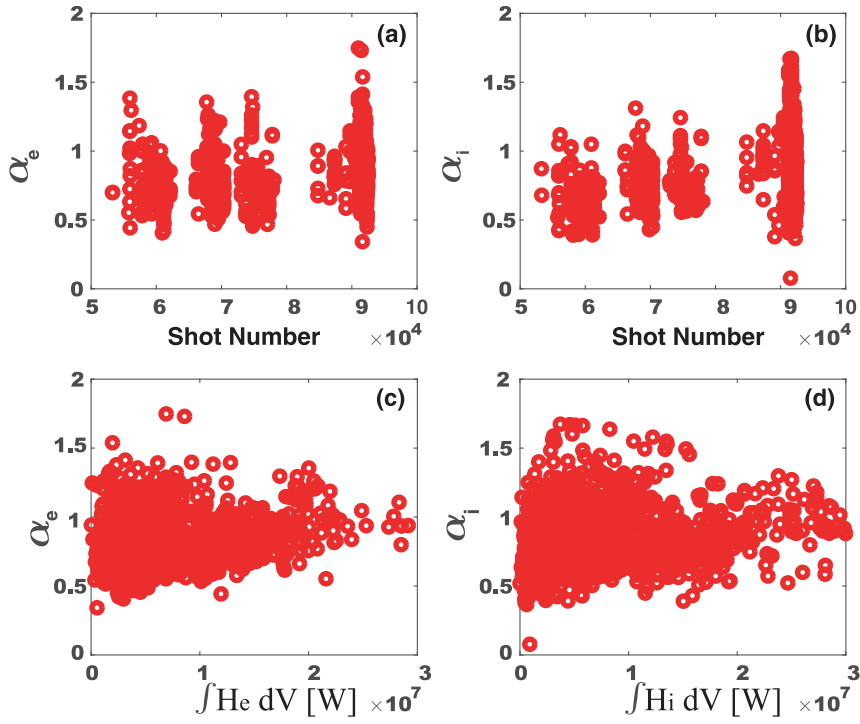

FIG. 2. The computed $\alpha_{e}$ [(a), (b)] and $\alpha_{i}[(\mathrm{c})$, (d)] as functions of the plasma shot number and the volume integrated net heating power for the selected JETPEAK dataset.

the confined plasma region. Note that due to the central limit theorem, a combination of Gaussian and Lévy processes will not result in a Gaussian process; therefore, finding a fractional index $\alpha \neq 2$ indicates that there are contributions from nonGaussian processes which resulted in such a fractal scaling.

In the current study, we have focused on the space fractional derivatives in the steady state to examine the nonlocality of transport. In principle, the temporal characteristics can be captured via a time-dependent $\alpha$ following Eq. (3), and we expect that the degree of nonlocality in space varies significantly as the plasma transitions from one regime to another, as suggested by the observed dispersion of $\alpha$ 's over the input power in Figs. 2(c) and 2(d). The fractional derivatives are integral derivatives connecting the local flux to a weight function of derivatives throughout the region of interest and thus represent the spatial nonlocal characteristics. A fractional time derivative, therefore, on a similar principle would connect the local flux in time to a weight function of derivatives throughout the time evolution window of interest and therefore accounts for the memory effects in transport. For example, in such a model, if an ITG mode with $\omega$ is active at some point during the pulse, and it is stabilized later on during the pulse (maybe as a result of fast ion stabilization effect), its impact will still be accounted for long after it has disappeared. Such memory effects may indeed be important for reaching a steady-state regime and should be examined. However, the addition of the time fractional derivative in Eq. (3) would introduce the term $\sim|\omega|^{\beta} \hat{p}(\mathbf{k}, \omega)$ in place of the first term. It is not obvious as yet how to interpret the values of $\alpha$ and $\beta$ from such an equation directly. A dispersion relation would be then required as $\omega=\omega(\mathbf{k})$. The derivation of such a relation requires a first principle fractional kinetic description of the plasma state, which is out of the scope of the current study.

In the following the results of our analysis for a selected database of the JET tokamak plasmas are presented. 


\section{THE JET DATASET AND THE RESULTS}

The analysis is performed using a large dataset from the JETPEAK database [47] of the JET carbon (C) and ITER like-wall (ILW) experiments. The analyzed dataset contains 1256 samples from 868 different plasma shots. Each sample is an average over a stationary state for $1 s$; therefore, the time derivative of the pressure in the relation (3) is neglected. Moreover, due to the time averaging, an average effect from transitional MHD behaviors such as edge localized modes (ELMs) and sawteeth crashes are accounted for within the analyzed profiles.

$T_{i}=T_{e}$ is assumed, but where charge exchange (CX) spectroscopy data are available measured $\mathrm{Ti}$ is used; $100 \%$ carbon and beryllium is the only present impurity in the $\mathrm{C}$ wall and ILW plasmas respectively. To compute the ion density, in the $\mathrm{C}$ wall plasmas measured effective charges are used. In ILW, uniform $Z_{\text {eff }}=1.2$ is assumed. For electrons the net heating is computed following $=H_{\mathrm{in}}-H_{\mathrm{Rad}}-H_{\mathrm{ie}}$, and for the ions the net heating is computed as $=H_{\mathrm{in}}+H_{\mathrm{ie}}$. Note that $H_{\mathrm{ie}}=0$ when $T_{i}=T_{e}$. The input heating profiles, i.e., $H_{\text {in }}$, are obtained from beam deposition code PENCIL [48] and for ICRH by the code PION [49]. $H_{\mathrm{Rad}}=20 \% H_{e}$ is assumed.

The degree of the globality of the transport processes were determined by computing $\alpha_{e, i}$ 's following the relation (4). An example of the computed $\alpha_{e}$ as function of mode numbers, $k_{R}$ and $k_{Z}$, for the plasma shot \#92071 is shown in Fig. 1. To test the accuracy of the Fourier space derivatives for the heating and pressure profiles, the first and second derivatives were computed both in the real and the Fourier spaces where good agreements were found. The value of fractional index for the first derivative is found $=1$ and for the second derivative $=2$, as expected. However, at higher mode numbers, the values suffer from numerical errors and thus, a high- $k$ cutoff (cutoff point is $\left.\left|k_{R, Z}\right|>60\right)$ is applied before averaging over $k_{R, Z}^{>}$. Figures 2(a)-2(d) show the values of $\alpha_{e, i}$ 's as functions of plasma shot numbers [Figs. 2(a) and 2(b)], where the shot numbers $<80000$ and $>80000$ are for the $\mathrm{C}$ wall and the ILW plasmas, respectively. Figures 2(c) and 2(d) show the $\alpha_{e, i}$ 's as functions of volume integrated net heating. As can be seen here, in all of the considered plasmas and for both electrons and ions, the computed fractional degrees are less than 2 . The nature of the heat transport in these plasmas, therefore, is expected to obey a nondiffusive model. The values of $\alpha_{e, i}$ cover a wide range from $\approx 0.5$ and $\approx 1.5$ due to the wide differences in the heating, fueling, and scenario schemes across these plasmas. However, a general convergence trend toward $\alpha_{e, i} \sim 1$ is observed with an increase in the total power [see Figs. 2(c) and 2(d)]. This convergence of $\alpha$ 's indicate that as the input power is increased, i.e., moving from L-mode to $\mathrm{H}$ mode plasmas, the underlying physics mechanisms change in a way to keep a natural relaxation of the steady-state profiles that is governed by a universal constant. Perhaps this is not surprising since high-power plasmas at JET are converging to similar types of plasma scenarios. At lower levels of the input power, however, the dispersion in $\alpha$ is large since there is a more significant variation between the plasma regimes at these power levels.

Figure 3 shows the histograms of the fractional index $\alpha_{e}$ (black line with square symbols) and $\alpha_{i}$ (red line with circular

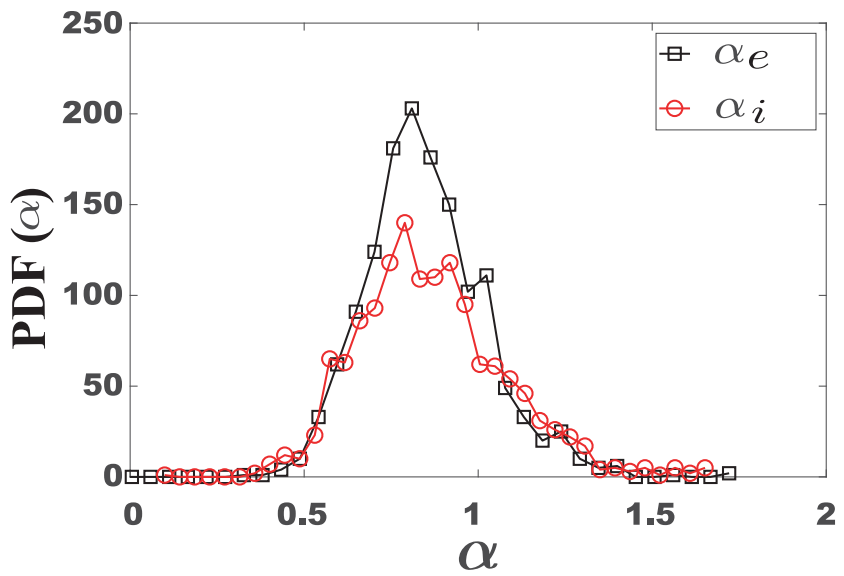

FIG. 3. The histogram of the computed $\alpha_{e}$ (black line with square symbols), and $\alpha_{i}$ (red line with circle symbols) for the selected JETPEAK dataset.

symbols). The peaks of the distributions are around $\alpha_{e, i} \approx 0.8$ and the standard deviations are $\mathrm{STD}_{\alpha_{e}}=0.17$ and $\mathrm{STD}_{\alpha_{i}}=$ 0.21 .

In the steady state, the relation (3) can be used to predict the pressure profiles from the heat deposition profile and $\alpha$ following the expression

$$
p_{e, i}(\mathbf{r})=\operatorname{IFT}\left[-|\mathbf{k}|^{-\alpha_{e, i}} \hat{H}_{e, i}(\mathbf{k})\right],
$$

where IFT represents inverse Fourier transformation. Figure 4 shows the predicted $p_{e}$ for the plasma discharge \#92071. The experimental profile (black solid line) is compared to the

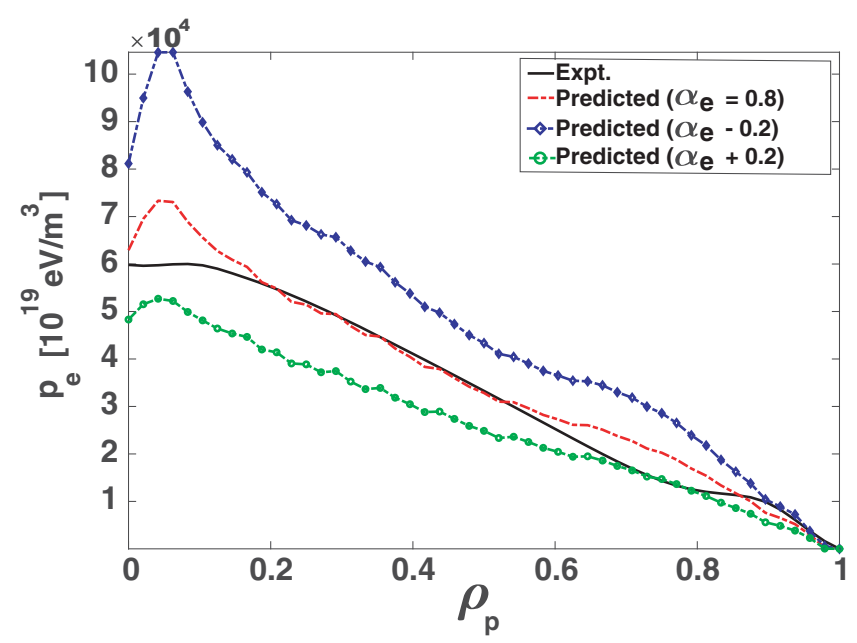

FIG. 4. Comparison of the experimental (black solid line) electron pressure profile versus normalized poloidal flux index $\rho_{p}$ and the predicted profile following the global transport model in Eq. (5) (red dash-dotted line) for the plasma discharges \#92071. The predicted pressure profiles with \pm 0.2 above (blue dotted line with diamond symbols) and below (green dotted line with circle symbols) the computed values of $\alpha_{e}$ are also shown. This discharge is an ELMy $\mathrm{H}$-mode pulse of hybrid type from ILW with $30 \mathrm{MW}$ total input power (25 MW NBI + 6.6 MW ICRH) and regular type I ELMs during the steady-state phase. 

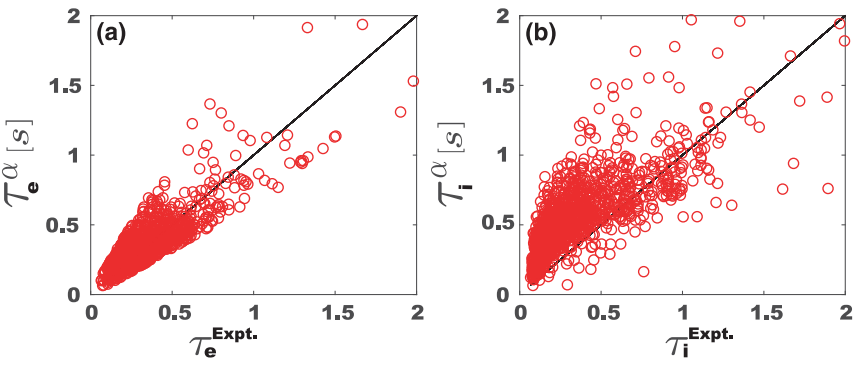

FIG. 5. The electron (a) and ion (b) energy confinement times, $\tau^{\text {Expt. }}$, computed from experimental pressure profiles as a function of the energy confinement time, $\tau^{\alpha}$, computed from the predicted pressure profiles following the relation (5), are shown.

profile predicted by using the computed $\alpha$ (dash-dotted red line). The predicted pressure profiles with \pm 0.2 above (blue dotted line with diamond symbols) and below (green dotted line with circle symbols) the computed value of $\alpha_{e}$ are also shown. As can be seen in Fig. 4, the best agreement between the experimental and the predicted pressure profiles is found for the computed value of $\alpha_{e}$.

\section{FIDELITY OF THE MODEL}

As a measure of fidelity of the global model (2), we have compared the ion and electron energy confinement times obtained from the experimental pressure profiles with the predicted ones following the expression $\tau=\int p_{e, i} d V / \int H_{e, i} d V$, where $H_{e, i}$ are the experimental heat deposition profiles. Figures 5(a) and 5(b) show the experimental $\tau_{\text {Expt. }}$ as a function of predicted $\tau_{\alpha}$. Here, the confinement times were computed by applying the volume integration over the whole plasma region from the core to the last closed flux surface. A good agreement is found for the electron energy confinement times. The agreement for the ions is less good with the predicted profiles mostly overestimated as compared to the experimental values within the JETPEAK dataset. However, due to the absence of $T_{i}$ measurements in many of the cases, the predictions for the $p_{i}$ profiles are limited.

\section{DISCUSSION AND CONCLUSION}

A global heat flux model based on a fractional derivative of plasma pressure is proposed for the heat transport in the fusion plasmas. The degree of the globality of the heat transport is defined through the power balance analysis. In the proposed fractional model, a single constant fractionality index, $\alpha$, is used as the dominant global scale dependence of the transport which is modified as compared to a diffusive model where $\alpha=2$. Our aim with this work is to find a minimalistic (i.e., with the least amount of parameters involved) transport model that can predict most plasmas, therefore ignoring the detailed nature and the classifications of the transport processes involved, and bundle their average (time/radial) effect into one constant parameter, $\alpha$.

The method was used to study the heat transport in a selected set of JET plasmas, including $\mathrm{C}$ wall and ITER like-wall, $\mathrm{L}$ mode, and $\mathrm{H}$ mode, with many different heating and fueling schemes from a wide range of experimental programs and plasmas with and without ELMs and various MHD modes active. The average fractional degree of the heat flux over the dataset was found as $\alpha \sim 0.8$. These results suggest that a global profile dependency between the net heating and the pressure profile in the JET plasmas exists, which results in the relaxation of the pressure profiles to that of the heating deposition profile with a global decay rate, i.e., $|\mathbf{k}|^{-\alpha}$. Thus, the profiles from the database of JET stationary phase are consistent with a constant fractional index $\alpha \approx 0.8$ on average, if one assumes a constant diffusivity profile and equal for all of the cases. Using the assumption of a universal transport coefficient, the actual behavior of the turbulent transport processes correspond to an $\alpha$ index significantly lower than 2 on average. The 0-D model was then used to predict the pressure profiles, and the comparison between the energy confinement time obtained from the experimental and the predicted kinetic profiles show a very good agreement, especially for the electrons. In the future, the proposed fractional transport model could be used as a feedback control for the plasma stability and control in real time by predicting profiles and thus providing a tool to detect and perhaps prevent or mitigate destructive transport events. It should be noted that in some cases there is a wider range of $\alpha$ parameters over the database in particular because these plasmas are in essence very different with one another regarding many factors such as the neutral beam injection (NBI) or ion cyclotron frequency heating (ICRH) input power, fueling scheme, edge localised mode (ELM) control, etc. What we are observing however, is that a significant number of these plasmas fall into a similar range for $\alpha$ parameter, especially as the input power is increased, yielding a transport model with predictive power in a wide parameter regime.

The most common transport models, e.g., TRANSP, JETTO, and ETS, assume locality of transport, resulting in the diffusive approach. Experimentally it has been found that at least two major observations do not agree with this assumption: (1) The predicted heat diffusivity coefficient in most cases does not provide the observed level of transport, and (2) global interplay among the core, edge, and SOL shows features of nonlocality of transport such as long-range correlations. Indeed, it is widely accepted that turbulent transport does not completely follow a locality law, in the sense that the relation between the flux and the gradient is not precisely linear, thus naturally yielding a fractional index differing from 2 .

Finally, we would like to make a note that this study is the first of its kind and its findings are expected to encourage further discussion on the validity and the mathematical limitations of our current models to address global properties of transport in fusion plasmas.

\section{ACKNOWLEDGMENTS}

We thank Dr. Tariq Rafiq, Henri Weison, and the JET task force leaders for sharing their wisdom with us during the course of this research and for their comments on an earlier version of the manuscript, although any errors are our own and should not tarnish the reputations of these esteemed persons. This work has been carried out within the framework of the EUROfusion Consortium and has received funding from the 
Euratom research and training programme 2014-2018 under Grant Agreement No. 633053. The views and opinions ex- pressed herein do not necessarily reflect those of the European Commission.
[1] H. Risken, The Fokker-Planck Equation: Methods of Solution and Applications, 2nd ed. (Springer, Berlin, 1989).

[2] F. Anselmet, Y. Gagne, E. J. Hopfinger, and R. A. Antonia, J. Fluid Mech. 140, 63 (1984).

[3] Z-S. She, E. Jackson, and S. A. Orszag, J. Sci. Comput. 3, 407 (1988).

[4] B. Castaing, Y. Gagne, and E. J. Hopfinger, Phys. D (Amsterdam, Neth.) 46, 177 (1990).

[5] N. Mordant, P. Metz, O. Michel, and J.-F. Pinton, Phys. Rev. Lett. 87, 214501 (2001).

[6] M. Wilczek, New J. Phys. 18, 125009 (2016).

[7] J. Jiménez, J. Fluid Mech. 376, 139 (1998).

[8] G. I. Barenblatt, Scaling, Self-Similarity, and Intermediate Asymptotics: Dimensional Analysis and Intermediate Asymptotics (Cambridge University Press, Cambridge, UK, 1996).

[9] U. Frisch, in Nonlinear Dynamics, edited by R. Helleman (Academy of Sciences, New York, 1980), p. 359.

[10] R. A. Moyer, R. D. Lehmer, T. E. Evans, R. W. Conn, and L. Schmitz, Plasma Phys. Control. Fusion 38, 1273 (1996).

[11] R. Jha, S. K. Mattoo, and Y. C. Saxena, Phys. Plasmas 4, 2982 (1997).

[12] B. A. Carreras, C. Hidalgo, E. Sanchez, M. A. Pedrosa, R. Balbin, I. Garcia-Cortes, B. van Milligen, D. Newman, and V. E. Lynch, Phys. Plasmas 3, 2664 (1996).

[13] B. A. Carreras, B. van Milligen, M. A. Pedrosa, R. Balbín, C. Hidalgo, D. E. Newman, E. Sánchez, M. Frances, I. GarcíaCortés, J. Bleuel, M. Endler, S. Davies, and G. F. Matthews, Phys. Rev. Lett. 80, 4438 (1998).

[14] B. A. Carreras, B. van Milligen, C. Hidalgo, R. Balbin, E. Sanchez, I. Garcia-Cortes, M. A. Pedrosa, J. Bleuel, and M. Endler, Phys. Rev. Lett. 83, 3653 (1999).

[15] J. A. Boedo, D. Rudakov, R. Moyer, S. Krasheninnikov, D. Whyte, G. McKee, G. Tynan, M. Schaffer, P. Stangeby, P. West, S. Allen, T. Evans, R. Fonck, E. Hallmann, A. Leonard, A. Mahdavi, G. Porter, M. Tillack, and G. Antar, Phys. Plasmas 8, 4826 (2001).

[16] R. Sànchez, D. E. Newman, and B. A. Carreras, Phys. Rev. Lett. 88, 068302 (2002).

[17] S. J. Zweben, D. P. Stotler, J. L. Terry, B. Labombard, M. Greenwald, M. Muterspaugh, C. S. Pitcher, K. Hallatschek, R. J. Maqueda, B. Rogers, J. L. Lowrance, V. J. Mastrocola, and G. F. Renda, and the Alcator C-Mod Group, Phys. Plasmas 9, 1981 (2002).

[18] B. LaBombard, M. Greenwald, R. L. Boivin, B. A. Carreras, J. W. Hughes, B. Lipschultz, D. Mossessian, C. S. Pitcher, J. L. Terry, S. J. Zweben, and the Alcator C-Mod team, Proceedings of 19th International Conference on Plasma Physics and Controlled Nuclear Fusion, Lyon, October 14-19 (2002) (IAEA, 2002) IAEA-CN-94/EX/D2-1.

[19] G. Y. Antar, G. Counsell, Y. Yu, B. Labombard, and P. Devynck, Phys. Plasmas 10, 419 (2003).

[20] J. L. Terry, S. J. Zweben, K. Hallatschek, B. LaBombard, R. J. Maqueda, B. Bai, C. J. Boswell, M. Greenwald, D. Kopon, W. M. Nevins, C. S. Pitcher, B. N. Rogers, D. P. Stotler, and X. Q. Xu, Phys. Plasmas 10, 1739 (2003).
[21] N. Lemoine and D. M. Grésillon, Phys. Plasmas 12, 092301 (2005).

[22] B. P. van Milligen, R. Sanchez, and C. Hidalgo, Phys. Rev. Lett. 109, 105001 (2012).

[23] M. F. J. Fox, F. van Wyk, A. R. Field, Y.-c. Ghim, F. I. Parra, A. A. Schekochihin, and MAST Team, Plasma Phys. Controlled Fusion 59, 034002 (2017).

[24] F. van Wyk, E. G. Highcock, A. R. Field, C. M. Roach, A. A. Schekochihin, F. I. Parra, and W. Dorland, Plasma Phys. Controlled Fusion 59, 114003 (2017).

[25] F. Parra, M. Barnes, and A. G. Peeters, Phys. Plasmas 18, 062501 (2011).

[26] J. C. Perez, W. Horton, R. D. Bengtson, and T. Carter, Phys. Plasmas 13, 055701 (2006).

[27] G. Dif-Pradalier, G. Hornung, P. Ghendrih, Y. Sarazin, F. Clairet, L. Vermare, P. H. Diamond, J. Abiteboul, T. CartierMichaud, C. Ehrlacher et al., Phys. Rev. Lett. 114, 085004 (2015).

[28] R. Sanchez, D. E. Newman, J. N. Leboeuf, V. K. Decyk, and B. A. Carreras, Phys. Rev. Lett. 101, 205002 (2008).

[29] D. del-Castillo-Negrete, B. A. Carreras, and V. E. Lynch, Phys. Rev. Lett. 94, 065003 (2005).

[30] J. Klafter, M. F. Shlesinger, and G. Zumofen, Phys. Today. 49, 33 (1996).

[31] R. Metzler and J. Klafter, Phys. Rep. 339, 1 (2000).

[32] P. Levy, Théorie De l'Addition Des Variables Aléatories (Gauthier-Villars, Paris, 1937).

[33] R. Jha, P. K. Kaw, S. K. Mattoo, C. V. S. Rao, Y. C. Saxena, and the ADITYA Team, Phys. Rev. Lett. 69, 1375 (1992).

[34] R. Jha, B. K. Joseph, R. Kalra, P. K. Kaw, S. K. Mattoo, D. Raju, C. V. S. Rao, Y. C. Saxena, A. Sen, and the ADITYA Team, Proceedings of 15th International Conference on Plasma Physics and Controlled Nuclear Fusion, Seville, 26 September-1 October, 1994 (IAEA, 1995), Vol. 1, p. 583.

[35] R. Jha, P. K. Kaw, D. R. Kulkarni, J. C. Parikh, and the ADITYA Team, Phys. Plasmas. 10, 699 (2003).

[36] S. Moradi, J. Anderson, and B. Weyssow, Phys. Plasmas. 18, 062106 (2011).

[37] J. Anderson, E. Kim, and S. Moradi, Phys. Plasmas. 21, 122109 (2014).

[38] S. Moradi, D. del Castillo Negreta, and J. Anderson, Phys. Plasmas 23, 090704 (2016).

[39] M. Romanelli and M. Ottaviani, Plasma Phys. Controlled Fusion 40, 1767 (1998).

[40] M. Romanelli, C. Bourdelle, and W. Dorland, Phys. Plasmas 11, 3845 (2004).

[41] M. Romanelli et al., Plasma Phys. Controlled Fusion 52, 045007 (2010).

[42] S. Moradi et al., Nucl. Fusion 54, 123016 (2014).

[43] H.-T. Kim, M. Romanelli, C. D. Challis, F. Rimini, L. Garzotti, E. Lerche, J. Buchanan, X. Yuan, and S. Kaye, Nucl. Fusion 58, 036020 (2018).

[44] T. Rafiq, A. H. Kritz, J. Weiland, A. Y. Pankin and L. Luo, Phys. Plasmas 20, 032506 (2013). 
[45] C. Bourdelle, J. Citrin, B. Baiocchi, A. Casati, P. Cottier, X. Garbet, F. Imbeaux, and JET Contributors, Plasma Phys. Control. Fusion 58, 014036 (2016).

[46] D. del Castillo Negrete, Nonlin. Proc. Geophys. 17, 795 (2010). [47] H. Weisen et al., Nucl. Fusion 57, 076029 (2017).
[48] C. D. Challis, J. G. Cordey, H. Hamnén, P. M. Stubberfield, J. P. Christiansen, E. Lazzaro, D. G. Muir, D. Stork, and E. Thompson, Nucl. Fusion 29, 563 (1989).

[49] L.-G. Eriksson, T. Hellsten, and U. Willén, Nucl. Fusion 33, 1037 (1993).

X. Litaudon, ${ }^{35}$ S. Abduallev, ${ }^{38}$ M. Abhangi, ${ }^{45}$ P. Abreu, ${ }^{52}$ M. Afzal, ${ }^{7}$ K. M. Aggarwal, ${ }^{29}$ T. Ahlgren, ${ }^{100}$ J. H. Ahn, ${ }^{8}$ L. Aho-Mantila, ${ }^{111}$ N. Aiba, ${ }^{68}$ M. Airila, ${ }^{111}$ R. Albanese, ${ }^{104}$ V. Aldred, ${ }^{7}$ D. Alegre, ${ }^{92}$ E. Alessi, ${ }^{44}$ P. Aleynikov, ${ }^{54}$ A. Alfier, ${ }^{12}$ A. Alkseev, ${ }^{71}$ M. Allinson, ${ }^{7}$ B. Alper, ${ }^{7}$ E. Alves,${ }^{52}$ G. Ambrosino, ${ }^{104}$ R. Ambrosino, ${ }^{105}$ L. Amicucci, ${ }^{89}$ V. Amosov, ${ }^{87}$

E. Andersson Sundén, ${ }^{22}$ M. Angelone, ${ }^{89}$ M. Anghel, ${ }^{84}$ C. Angioni,${ }^{61}$ L. Appel, ${ }^{7}$ C. Appelbee, ${ }^{7}$ P. Arena, ${ }^{30}$ M. Ariola, ${ }^{105}$ H. Arnichand, ${ }^{8}$ S. Arshad, ${ }^{40}$ A. Ash,${ }^{7}$ N. Ashikawa,${ }^{67}$ V. Aslanyan, ${ }^{63}$ O. Asunta, ${ }^{1}$ F. Auriemma, ${ }^{12}$ Y. Austin, ${ }^{7}$ L. Avotina, ${ }^{102}$ M. D. Axton, ${ }^{7}$ C. Ayres, ${ }^{7}$ M. Bacharis, ${ }^{24}$ A. Baciero, ${ }^{56}$ D. Baião, ${ }^{52}$ S. Bailey, ${ }^{7}$ A. Baker, ${ }^{7}$ I. Balboa, ${ }^{7}$ M. Balden, ${ }^{61}$ N. Balshaw, ${ }^{7}$ R. Bament, ${ }^{7}$ J. W. Banks, ${ }^{7}$ Y. F. Baranov, ${ }^{7}$ M. A. Barnard,${ }^{7}$ D. Barnes, ${ }^{7}$ M. Barnes ${ }^{27}$ R. Barnsley, ${ }^{54}$ A. Baron Wiechec, ${ }^{7}$ L. Barrera Orte, ${ }^{34}$ M. Baruzzo, ${ }^{12}$ V. Basiuk, ${ }^{8}$ M. Bassan, ${ }^{54}$ R. Bastow, ${ }^{7}$ A. Batista, ${ }^{52}$ P. Batistoni, ${ }^{89}$ R. Baughan, ${ }^{7}$ B. Bauvir, ${ }^{54}$ L. Baylor, ${ }^{72}$ B. Bazylev, ${ }^{55}$ J. Beal, ${ }^{109}$ P. S. Beaumont, ${ }^{7}$ M. Beckers,${ }^{38}$ B. Beckett, ${ }^{7}$ A. Becoulet, ${ }^{8}$ N. Bekris, ${ }^{35}$ M. Beldishevski, ${ }^{7}$ K. Bell, ${ }^{7}$ F. Belli, ${ }^{89}$ M. Bellinger, ${ }^{7}$ É. Belonohy, ${ }^{61}$ N. Ben Ayed, ${ }^{7}$ N. A. Benterman, ${ }^{7}$ H. Bergsäker, ${ }^{41}$ J. Bernardo, ${ }^{52}$ M. Bernert, ${ }^{61}$ M. Berry, ${ }^{7}$ L. Bertalot,${ }^{54}$ C. Besliu, ${ }^{7}$ M. Beurskens, ${ }^{62}$ B. Bieg, ${ }^{60}$ J. Bielecki, ${ }^{46}$ T. Biewer, ${ }^{72}$ M. Bigi, ${ }^{12}$ P. Bìlkovà, ${ }^{49}$ F. Binda, ${ }^{22}$ A. Bisoffi, ${ }^{31}$ J. P. S. Bizarro, ${ }^{52}$ C. Björkas, ${ }^{100}$ J. Blackburn, ${ }^{7}$ K. Blackman, ${ }^{7}$ T. R. Blackman, ${ }^{7}$ P. Blanchard, ${ }^{33}$ P. Blatchford, ${ }^{7}$ V. Bobkov, ${ }^{61}$ A. Boboc, ${ }^{7}$ G. Bodnàr, ${ }^{112}$ O. Bogar, ${ }^{18}$ I. Bolshakova, ${ }^{59}$ T. Bolzonella, ${ }^{12}$ N. Bonanomi, ${ }^{96}$ F. Bonelli, ${ }^{55}$ J. Boom, ${ }^{61}$ J. Booth, ${ }^{7}$ D. Borba,${ }^{35,52}$ D. Borodin, ${ }^{38}$ I. Borodkina, ${ }^{38}$ A. Botrugno, ${ }^{89}$ C. Bottereau, ${ }^{8}$ P. Boulting, ${ }^{7}$ C. Bourdelle, ${ }^{8}$ M. Bowden, ${ }^{7}$ C. Bower, ${ }^{7}$ C. Bowman, ${ }^{109}$ T. Boyce, ${ }^{7}$ C. Boyd, ${ }^{7}$ H. J. Boyer, ${ }^{7}$ J. M. A. Bradshaw, ${ }^{7}$ V. Braic, ${ }^{86}$ R. Bravanec, ${ }^{39}$ B. Breizman, ${ }^{106}$ S. Bremond, ${ }^{8}$ P. D. Brennan, ${ }^{7}$ S. Breton, ${ }^{8}$ A. Brett, ${ }^{7}$ S. Brezinsek, ${ }^{38}$

M. D. J. Bright, ${ }^{7}$ M. Brix, ${ }^{7}$ W. Broeckx, ${ }^{77}$ M. Brombin, ${ }^{12}$ A. Brosawski, ${ }^{64}$ D. P. D. Brown, ${ }^{7}$ M. Brown, ${ }^{7}$ E. Bruno, ${ }^{54}$ J. Bucalossi, ${ }^{8}$ J. Buch, ${ }^{45}$ J. Buchanan, ${ }^{7}$ M. A. Buckley, ${ }^{7}$ R. Budny, ${ }^{75}$ H. Bufferand, ${ }^{8}$ M. Bulman, ${ }^{7}$ N. Bulmer, ${ }^{7}$ P. Bunting, ${ }^{7}$

P. Buratti, ${ }^{89}$ A. Burckhart, ${ }^{61}$ A. Buscarino, ${ }^{30}$ A. Busse,${ }^{7}$ N. K. Butler, ${ }^{7}$ I. Bykov, ${ }^{41}$ J. Byrne, ${ }^{7}$ P. Cahyna, ${ }^{49}$ G. Calabrò ${ }^{89}$

I. Calvo, ${ }^{56}$ Y. Camenen, ${ }^{4}$ P. Camp, ${ }^{7}$ D. C. Campling, ${ }^{7}$ J. Cane, ${ }^{7}$ B. Cannas, ${ }^{17}$ A. J. Capel, ${ }^{7}$ P. J. Card, ${ }^{7}$ A. Cardinali, ${ }^{89}$

P. Carman, ${ }^{7}$ M. Carr, ${ }^{7}$ D. Carralero, ${ }^{61}$ L. Carraro, ${ }^{12}$ B. B. Carvalho, ${ }^{52}$ I. Carvalho, ${ }^{52}$ P. Carvalho, ${ }^{52}$ F. J. Casson, ${ }^{7}$ C. Castaldo, ${ }^{89}$

N. Catarino, ${ }^{52}$ J. Caumont, ${ }^{7}$ F. Causa, ${ }^{89}$ R. Cavazzana, ${ }^{12}$ K. Cave-Ayland, ${ }^{7}$ M. Cavinato, ${ }^{12}$ M. Cecconello, ${ }^{22}$ S. Ceccuzzi, ${ }^{89}$

E. Cecil, ${ }^{75}$ A. Cenedese, ${ }^{12}$ R. Cesario, ${ }^{89}$ C. D. Challis, ${ }^{7}$ M. Chandler, ${ }^{7}$ D. Chandra, ${ }^{45}$ C. S. Chang, ${ }^{75}$ A. Chankin, ${ }^{61}$

I. T. Chapman, ${ }^{7}$ S. C. Chapman, ${ }^{28}$ M. Chernyshova, ${ }^{48}$ G. Chitarin, ${ }^{12}$ G. Ciraolo, ${ }^{8}$ D. Ciric,${ }^{7}$ J. Citrin, ${ }^{37}$ F. Clairet ${ }^{8}$ E. Clark, ${ }^{7}$ M. Clark, ${ }^{7}$ R. Clarkson, ${ }^{7}$ D. Clatworthy, ${ }^{7}$ C. Clements, ${ }^{7}$ M. Cleverly, ${ }^{7}$ J. P. Coad, ${ }^{7}$ P. A. Coates, ${ }^{7}$ A. Cobalt, ${ }^{7}$ V. Coccorese, ${ }^{104}$ V. Cocilovo, ${ }^{89}$ S. Coda, ${ }^{33}$ R. Coelho, ${ }^{52}$ J. W. Coenen, ${ }^{38}$ I. Coffey, ${ }^{29}$ L. Colas, ${ }^{8}$ S. Collins, ${ }^{7}$ D. Conka, ${ }^{102}$ S. Conroy, ${ }^{22}$ N. Conway, ${ }^{7}$ D. Coombs, ${ }^{7}$ D. Cooper, ${ }^{7}$ S. R. Cooper, ${ }^{7}$ C. Corradino, ${ }^{30}$ Y. Corre,${ }^{8}$ G. Corrigan, ${ }^{7}$ S. Cortes, ${ }^{52}$ D. Coster, ${ }^{61}$ A. S. Couchman, ${ }^{7}$ M. P. Cox, ${ }^{7}$ T. Craciunescu, ${ }^{85}$ S. Cramp,${ }^{7}$ R. Craven, ${ }^{7}$ F. Crisanti, ${ }^{89}$ G. Croci, ${ }^{96}$ D. Croft, ${ }^{7}$ K. Crombé, ${ }^{15}$ R. Crowe, ${ }^{7}$ N. Cruz, ${ }^{52}$ G. Cseh, ${ }^{112}$ A. Cufar, ${ }^{80}$ A. Cullen, ${ }^{7}$ M. Curuia, ${ }^{84}$ A. Czarnecka, ${ }^{48}$ H. Dabirikhah, ${ }^{7}$ P. Dalgliesh, ${ }^{7}$ S. Dalley, ${ }^{7}$ J. Dankowski, ${ }^{46}$ D. Darrow, ${ }^{75}$ O. Davies, ${ }^{7}$ W. Davis,${ }^{54,75}$ C. Day, ${ }^{55}$ I. E. Day, ${ }^{7}$ M. De Bock, ${ }^{54}$ A. de Castro, ${ }^{56}$ E. de la Cal, ${ }^{56}$ E. de la Luna, ${ }^{56}$ G. De Masi, ${ }^{12}$ J. L. de Pablos, ${ }^{56}$ G. De Temmerman, ${ }^{54}$ G. De Tommasi, ${ }^{104}$ P. de Vries,${ }^{54}$ K. Deakin, ${ }^{7}$ J. Deane, ${ }^{7}$ F. Degli Agostini, ${ }^{12}$ R. Dejarnac, ${ }^{49}$ E. Delabie, ${ }^{72}$ N. den Harder, ${ }^{37}$ R. O. Dendy, ${ }^{7}$ J. Denis, ${ }^{8}$ P. Denner, ${ }^{38}$

S. Devaux $,{ }^{61}, 103$ P. Devynck, ${ }^{8}$ F. Di Maio,${ }^{54}$ A. Di Siena, ${ }^{61}$ C. Di Troia, ${ }^{89}$ P. Dinca,${ }^{85}$ R. Dinca, ${ }^{61}$ B. Ding, ${ }^{50}$ T. Dittmar, ${ }^{38}$ H. Doerk, ${ }^{61}$ R. P. Doerner, ${ }^{9}$ T. Donné, ${ }^{44}$ S. E. Dorling, ${ }^{7}$ S. Dormido-Canto, ${ }^{92}$ S. Doswon, ${ }^{7}$ D. Douai, ${ }^{8}$ P. T. Doyle, ${ }^{7}$

A. Drenik, ${ }^{61,80}$ P. Drewelow, ${ }^{62}$ P. Drews, ${ }^{38} \mathrm{Ph}$. Duckworth, ${ }^{54}$ R. Dumont, ${ }^{8}$ P. Dumortier, ${ }^{57}$ D. Dunai, ${ }^{112}$ M. Dunne, ${ }^{61} \mathrm{I}$. Duran, ${ }^{49}$ F. Durodié, ${ }^{57}$ P. Dutta, ${ }^{45}$ B. P. Duval, ${ }^{33}$ R. Dux, ${ }^{61}$ K. Dylst, ${ }^{77}$ N. Dzysiuk, ${ }^{22}$ P. V. Edappala, ${ }^{45}$ J. Edmond, ${ }^{7}$ A. M. Edwards, ${ }^{7}$ J. Edwards, ${ }^{7}$ Th. Eich, ${ }^{61}$ A. Ekedahl, ${ }^{8}$ R. El-Jorf, ${ }^{7}$ C. G. Elsmore, ${ }^{7}$ M. Enachescu, ${ }^{83}$ G. Ericsson, ${ }^{22}$ F. Eriksson, ${ }^{16}$ J. Eriksson, ${ }^{22}$ L. G. Eriksson, ${ }^{36}$ B. Esposito, ${ }^{89}$ S. Esquembri, ${ }^{93}$ H. G. Esser, ${ }^{38}$ D. Esteve,${ }^{8}$ B. Evans, ${ }^{7}$ G. E. Evans, ${ }^{7}$ G. Evison, ${ }^{7}$ G. D. Ewart, ${ }^{7}$ D. Fagan, ${ }^{7}$ M. Faitsch, ${ }^{61}$ D. Falie, ${ }^{85}$ A. Fanni, ${ }^{17}$ A. Fasoli, ${ }^{33}$ J. M. Faustin, ${ }^{33}$ N. Fawlk, ${ }^{7}$ L. Fazendeiro, ${ }^{52}$ N. Fedorczak, ${ }^{8}$ R. C. Felton, ${ }^{7}$ K. Fenton, ${ }^{7}$ A. Fernades,${ }^{52}$ H. Fernandes,${ }^{52}$ J. Ferreira ${ }^{52}$ J. A. Fessey, ${ }^{7}$ O. Février, ${ }^{8}$ O. Ficker, ${ }^{49}$ A. Field, ${ }^{7}$ S. Fietz, ${ }^{61}$ A. Figueiredo, ${ }^{52}$ J. Figueiredo, ${ }^{52,35}$ A. Fil,${ }^{8}$ P. Finburg, ${ }^{7}$ M. Firdaouss ${ }^{8}$ U. Fischer, ${ }^{55}$ L. Fittill, ${ }^{7}$ M. Fitzgerald, ${ }^{7}$ D. Flammini, ${ }^{89}$ J. Flanagan, ${ }^{7}$ C. Fleming, ${ }^{7}$ K. Flinders, ${ }^{7}$ N. Fonnesu, ${ }^{89}$ J. M. Fontdecaba, ${ }^{56}$ A. Formisano, ${ }^{78}$ L. Forsythe, ${ }^{7}$ L. Fortuna, ${ }^{30}$ E. Fortuna-Zalesna, ${ }^{19}$ M. Fortune, ${ }^{7}$ S. Foster, ${ }^{7}$ T. Franke, ${ }^{34}$ T. Franklin, ${ }^{7}$ M. Frasca, ${ }^{30}$ L. Frassinetti, ${ }^{41}$ M. Freisinger, ${ }^{38}$ R. Fresa, ${ }^{97}$ D. Frigione, ${ }^{89}$ V. Fuchs, ${ }^{49}$ D. Fuller, ${ }^{35}$ S. Futatani, ${ }^{6}$ J. Fyvie, ${ }^{7}$ K. Gàl, ${ }^{34,61}$ D. Galassi, ${ }^{2}$

K. Galazka, ${ }^{48}$ J. Galdon-Quiroga,${ }^{91}$ J. Gallagher, ${ }^{7}$ D. Gallart, ${ }^{6}$ R. Galvão, ${ }^{10}$ X. Gao,${ }^{50}$ Y. Gao, ${ }^{38}$ J. Garcia, ${ }^{8}$

A. Garcia-Carrasco, ${ }^{41}$ M. Garca-Munoz, ${ }^{11}$ J.-L. Gardarein, ${ }^{3}$ L. Garzotti, ${ }^{7}$ P. Gaudio, ${ }^{44}$ E. Gauthier, ${ }^{8}$ D. F. Gear, ${ }^{7}$ S. J. Gee, ${ }^{7}$ B. Geiger, ${ }^{61}$ M. Gelfusa, ${ }^{94}$ S. Gerasimov, ${ }^{7}$ G. Gervasini, ${ }^{44}$ M. Gethins, ${ }^{7}$ Z. Ghani, ${ }^{7}$ M. Ghate, ${ }^{45}$ M. Gherendi, ${ }^{85}$

J. C. Giacalone, ${ }^{8}$ L. Giacomelli, ${ }^{44}$ C. S. Gibson, ${ }^{7}$ T. Giegerich, ${ }^{55}$ C. Gil, ${ }^{8}$ L. Gil, ${ }^{52}$ S. Gilligan, ${ }^{7}$ D. Gin, ${ }^{53}$ E. Giovannozzi, ${ }^{89}$ J. B. Girardo, ${ }^{8}$ C. Giroud, ${ }^{7}$ G. Giruzzi, ${ }^{8}$ S. Glöggler, ${ }^{61}$ J. Godwin, ${ }^{7}$ J. Goff, ${ }^{7}$ P. Gohil, ${ }^{42}$ V. Goloborod'ko, ${ }^{101}$ R. Gomes ${ }^{52}$ B. Goncalves, ${ }^{52}$ M. Goniche, ${ }^{8}$ M. Goodliffe, ${ }^{7}$ A. Goodyear, ${ }^{7}$ G. Gorini, ${ }^{96}$ M. Gosk, ${ }^{64}$ R. Goulding, ${ }^{75}$ A. Goussarov, ${ }^{77}$ 
R. Gowland, ${ }^{7}$ B. Graham, ${ }^{7}$ M. E. Graham, ${ }^{7}$ J. P. Graves, ${ }^{33}$ N. Grazier, ${ }^{7}$ P. Grazier, ${ }^{7}$ N. R. Green, ${ }^{7}$ H. Greuner, ${ }^{61}$ B. Grierson, ${ }^{75}$ F. S. Griph, ${ }^{7}$ C. Grisolia,${ }^{8}$ D. Grist, ${ }^{7}$ M. Groth, ${ }^{1}$ R. Grove,${ }^{72}$ C. N. Grundy, ${ }^{7}$ J. Grzonka, ${ }^{19}$ D. Guard, ${ }^{7}$ C. Guérard, ${ }^{34}$

C. Guillemaut, ${ }^{8,52}$ R. Guirlet, ${ }^{8}$ C. Gurl, ${ }^{7}$ H. H. Utoh, ${ }^{68}$ L. J. Hackett, ${ }^{7}$ S. Hacquin,,${ }^{8,35}$ A. Hagar, ${ }^{7}$ R. Hager, ${ }^{75}$ A. Hakola, ${ }^{111}$ M. Halitovs, ${ }^{102}$ S. J. Hall, ${ }^{7}$ S. P. Hallworth Cook, ${ }^{7}$ C. Hamlyn-Harris, ${ }^{7}$ K. Hammond, ${ }^{7}$ C. Harrington, ${ }^{7}$ J. Harrison, ${ }^{7}$ D. Harting, ${ }^{7}$ F. Hasenbeck, ${ }^{38}$ Y. Hatano, ${ }^{107}$ D. R. Hatch, ${ }^{106}$ T. D. V. Haupt, ${ }^{7}$ J. Hawes, ${ }^{7}$ N. C. Hawkes, ${ }^{7}$ J. Hawkins, ${ }^{7}$ P. Hawkins, ${ }^{7}$ P. W. Haydon, ${ }^{7}$ N. Hayter, ${ }^{7}$ S. Hazel, ${ }^{7}$ P. J. L. Heesterman, ${ }^{7}$ K. Heinola, ${ }^{100}$ C. Hellesen, ${ }^{22}$ T. Hellsten, ${ }^{41}$ W. Helou, ${ }^{8}$ O. N. Hemming, ${ }^{7}$ T. C. Hender, ${ }^{7}$ M. Henderson, ${ }^{54}$ S. S. Henderson, ${ }^{21}$ R. Henriques, ${ }^{52}$ D. Hepple, ${ }^{7}$ G. Hermon, ${ }^{7}$ P. Hertout, ${ }^{8}$ C. Hidalgo, ${ }^{56}$ E. G. Highcock, ${ }^{27}$ M. Hill, ${ }^{7}$ J. Hillairet, ${ }^{8}$ J. Hillesheim, ${ }^{7}$ D. Hillis, ${ }^{72}$ K. Hizanidis, ${ }^{69}$

A. Hjalmarsson, ${ }^{22}$ J. Hobirk, ${ }^{61}$ E. Hodille ${ }^{8}$ C. H. A. Hogben, ${ }^{7}$ G. M. D. Hogeweij, ${ }^{37}$ A. Hollingsworth, ${ }^{7}$ S. Hollis, ${ }^{7}$ D. A. Homfray, ${ }^{7}$ J. Horàcek, ${ }^{49}$ G. Hornung, ${ }^{15}$ A. R. Horton, ${ }^{7}$ L. D. Horton, ${ }^{36}$ L. Horvath, ${ }^{109}$ S. P. Hotchin, ${ }^{7}$ M. R. Hough, ${ }^{7}$ P. J. Howarth, ${ }^{7}$ A. Hubbard, ${ }^{63}$ A. Huber, ${ }^{38}$ V. Huber, ${ }^{38}$ T. M. Huddleston, ${ }^{7}$ M. Hughes, ${ }^{7}$ G. T. A. Huijsmans, ${ }^{54}$ C. L. Hunter, ${ }^{7}$ P. Huynh, ${ }^{8}$ A. M. Hynes, ${ }^{7}$ D. Iglesias, ${ }^{7}$ N. Imazawa, ${ }^{6}$ F. Imbeaux, ${ }^{8}$ M. Imrìsek,${ }^{49}$ M. Incelli, ${ }^{108}$ P. Innocente, ${ }^{12}$ M. Irishkin, ${ }^{8}$ I. Ivanova-Stanik, ${ }^{48}$ S. Jachmich, ${ }^{57,35}$ A. S. Jacobsen, ${ }^{82}$ P. Jacquet, ${ }^{7}$ J. Jansons, ${ }^{102}$ A. Jardin, ${ }^{8}$ A. Järvinen, ${ }^{1}$ F. Jaulmes,${ }^{37}$ S. Jednoróq, ${ }^{48}$ I. Jenkins, ${ }^{7}$ C. Jeong, ${ }^{20}$ I. Jepu, ${ }^{85}$ E. Joffrin, ${ }^{8}$ R. Johnson, ${ }^{7}$ T. Johnson, ${ }^{41}$ Jane Johnston, ${ }^{7}$ L. Joita, ${ }^{7}$ G. Jones, ${ }^{7}$ T. T. C. Jones, ${ }^{7}$ K. K. Hoshino, ${ }^{68}$ A. Kallenbach, ${ }^{61}$ K. Kamiya, ${ }^{68}$ J. Kaniewski, ${ }^{7}$ A. Kantor, ${ }^{7}$ A. Kappatou, ${ }^{61}$ J. Karhunen, ${ }^{1}$ D. Karkinsky, ${ }^{7}$ I. Karnowska, ${ }^{7}$ M. Kaufman, ${ }^{72}$ G. Kaveney, ${ }^{7}$ Y. Kazakov, ${ }^{57}$ V. Kazantzidis, ${ }^{69}$ D. L. Keeling, ${ }^{7}$ T. Keenan, ${ }^{7}$

J. Keep, ${ }^{7}$ M. Kempenaars, ${ }^{7}$ C. Kennedy, ${ }^{7}$ D. Kenny, ${ }^{7}$ J. Kent, ${ }^{7}$ O. N. Kent, ${ }^{7}$ E. Khilkevich, ${ }^{53}$ H. T. Kim, ${ }^{35}$ H. S. Kim, ${ }^{79}$

A. Kinch, ${ }^{7}$ C. King, ${ }^{7}$ D. King, ${ }^{7}$ R. F. King, ${ }^{7}$ D. J. Kinna, ${ }^{7}$ V. Kiptily,${ }^{7}$ A. Kirk, ${ }^{7}$ K. Kirov, ${ }^{7}$ A. Kirschner, ${ }^{38}$ G. Kizane, ${ }^{102}$ C. Klepper, ${ }^{72}$ A. Klix, ${ }^{55}$ P. Knight, ${ }^{7}$ S. J. Knipe, ${ }^{7}$ S. Knott, ${ }^{95}$ T. Kobuchi, ${ }^{68}$ F. Köchl, ${ }^{110}$ G. Kocsis, ${ }^{112}$ I. Kodeli, ${ }^{80}$ L. Kogan, ${ }^{7}$ D. Kogut, ${ }^{8}$ S. Koivuranta, ${ }^{111}$ Y. Kominis, ${ }^{69}$ M. Köppen, ${ }^{38}$ B. Kos,${ }^{80}$ T. Koskela, ${ }^{1}$ H. R. Koslowski, ${ }^{38}$ M. Koubiti, ${ }^{4}$ M. Kovari, ${ }^{7}$ E. Kowalska-Strzeciwilk, ${ }^{48}$ A. Krasilnikov, ${ }^{87}$ V. Krasilnikov, ${ }^{87}$ N. Krawczyk, ${ }^{48}$ M. Kresina, ${ }^{8}$ K. Krieger, ${ }^{61}$ A. Krivska, ${ }^{57}$

U. Kruezi, ${ }^{7}$ I. Ksiazek, ${ }^{47}$ A. Kukushkin, ${ }^{71}$ A. Kundu, ${ }^{45}$ T. Kurki-Suonio, ${ }^{1}$ S. Kwak, ${ }^{20}$ R. Kwiatkowski, ${ }^{64}$ O. J. Kwon, ${ }^{13}$ L. Laguardia, ${ }^{44}$ A. Lahtinen, ${ }^{100}$ A. Laing, ${ }^{7}$ N. Lam, ${ }^{7}$ H. T. Lambertz, ${ }^{38}$ C. Lane, ${ }^{7}$ P. T. Lang, ${ }^{61}$ S. Lanthaler, ${ }^{33}$ J. Lapins, ${ }^{102}$ A. Lasa, ${ }^{100}$ J. R. Last, ${ }^{7}$ E. Laszynska, ${ }^{48}$ R. Lawless, ${ }^{7}$ A. Lawson, ${ }^{7}$ K. D. Lawson, ${ }^{7}$ A. Lazaros, ${ }^{69}$ E. Lazzaro, ${ }^{44}$ J. Leddy, ${ }^{109}$ S. Lee ${ }^{65}$ X. Lefebvre, ${ }^{7}$ H. J. Leggate, ${ }^{32}$ J. Lehmann, ${ }^{7}$ M. Lehnen, ${ }^{54}$ D. Leichtle, ${ }^{40}$ P. Leichuer, ${ }^{7}$ F. Leipold, ${ }^{54,82}$ I. Lengar, ${ }^{80}$ M. Lennholm, ${ }^{36}$ E. Lerche, ${ }^{57}$ A. Lescinskis, ${ }^{102}$ S. Lesnoj, ${ }^{7}$ E. Letellier, ${ }^{7}$ M. Leyland, ${ }^{109}$ W. Leysen, ${ }^{77}$ L. Li ${ }^{38}$ Y. Liang, ${ }^{38}$ J. Likonen, ${ }^{111}$ J. Linke, ${ }^{38}$ Ch. Linsmeier, ${ }^{38}$ B. Lipschultz, ${ }^{109}$ G. Liu, ${ }^{54}$ Y. Liu, ${ }^{50}$ V. P. Lo Schiavo, ${ }^{104}$ T. Loarer, ${ }^{8}$ A. Loarte, ${ }^{54}$ R. C. Lobel, ${ }^{7}$ B. Lomanowski, ${ }^{1}$ P. J. Lomas, ${ }^{7}$ J. Lönnroth, ${ }^{1,35}$ J. M. López, ${ }^{93}$ J. López-Razola, ${ }^{56}$ R. Lorenzini, ${ }^{12}$ U. Losada, ${ }^{56}$ J. J. Lovell, ${ }^{7}$ A. B. Loving, ${ }^{7}$ C. Lowry, ${ }^{36}$ T. Luce, ${ }^{42}$ R. M. A. Lucock, ${ }^{7}$ A. Lukin, ${ }^{73}$ C. Luna,${ }^{5}$ M. Lungaroni, ${ }^{94}$ C. P. Lungu, ${ }^{85}$ M. Lungu, ${ }^{85}$ A. Lunniss, ${ }^{109}$ I. Lupelli, ${ }^{7}$ A. Lyssoivan, ${ }^{57}$ N. Macdonald, ${ }^{7}$ P. Macheta, ${ }^{7}$ K. Maczewa, ${ }^{7}$ B. Magesh, ${ }^{45}$ P. Maget, ${ }^{8}$ C. Maggi, ${ }^{7}$ H. Maier, ${ }^{61}$ J. Mailloux, ${ }^{7}$ T. Makkonen, ${ }^{1}$ R. Makwana, ${ }^{45}$ A. Malaquias,${ }^{52}$ A. Malizia, ${ }^{94}$ P. Manas, ${ }^{4}$ A. Manning, ${ }^{7}$ M. E. Manso, ${ }^{52}$ P. Mantica, ${ }^{44}$ M. Mantsinen, ${ }^{6}$ A. Manzanares, ${ }^{90}$ Ph. Maquet, ${ }^{54}$ Y. Marandet, ${ }^{4}$ N. Marcenko, ${ }^{87}$ C. Marchetto,${ }^{44}$ O. Marchuk, ${ }^{38}$ M. Marinelli, ${ }^{94}$ M. Marinucci, ${ }^{89}$ T. Markovic, ${ }^{49}$ D. Marocco, ${ }^{89}$ L. Marot, ${ }^{26}$ C. A. Marren, ${ }^{7}$ R. Marshal, ${ }^{7}$ A. Martin, ${ }^{7}$ Y. Martin, ${ }^{33}$ A. Martín de Aguilera, ${ }^{56}$ F. J. Martínez, ${ }^{92}$ J. R. Martín-Solís, ${ }^{14}$ Y. Martynova, ${ }^{38}$ S. Maruyama, ${ }^{54}$ A. Masiello, ${ }^{12}$ M. Maslov, ${ }^{7}$ S. Matejcik, ${ }^{18}$ M. Mattei, ${ }^{78}$ G. F. Matthews, ${ }^{7}$ F. Maviglia, ${ }^{11}$ M. Mayer, ${ }^{61}$ M. L. Mayoral, ${ }^{34}$ T. May-Smith, ${ }^{7}$ D. Mazon, ${ }^{8}$ C. Mazzotta, ${ }^{89}$ R. McAdams, ${ }^{7}$ P. J. McCarthy, ${ }^{95}$ K. G. McClements, ${ }^{7}$ O. McCormack, ${ }^{12}$ P. A. McCullen, ${ }^{7}$ D. McDonald,${ }^{34}$ S. McIntosh, ${ }^{7}$ R. McKean, ${ }^{7}$ J. McKehon, ${ }^{7}$ R. C. Meadows,${ }^{7}$ A. Meakins, ${ }^{7}$ F. Medina,${ }^{56}$ M. Medland, ${ }^{7}$ S. Medley, ${ }^{7}$ S. Meigh,${ }^{7}$ A. G. Meigs, ${ }^{7}$ G. Meisl, ${ }^{61}$ S. Meitner,${ }^{72}$ L. Meneses, ${ }^{52}$ S. Menmuir, ${ }^{7,41}$ K. Mergia, ${ }^{70}$

I. R. Merrigan, ${ }^{7}$ Ph. Mertens, ${ }^{38}$ S. Meshchaninov, ${ }^{87}$ A. Messiaen,${ }^{57}$ H. Meyer, ${ }^{7}$ S. Mianowski, ${ }^{64}$ R. Michling, ${ }^{54}$

D. Middleton-Gear, ${ }^{7}$ J. Miettunen, ${ }^{1}$ F. Militello, ${ }^{7}$ E. Militello-Asp, ${ }^{7}$ G. Miloshevsky, ${ }^{76}$ F. Mink, ${ }^{61}$ S. Minucci, ${ }^{104}$ Y. Miyoshi ${ }^{68}$ J. Mlynàr, ${ }^{49}$ D. Molina, ${ }^{8}$ I. Monakhov, ${ }^{7}$ M. Moneti, ${ }^{108}$ R. Mooney, ${ }^{7}$ S. Moradi,${ }^{57}$ S. Mordijck, ${ }^{42}$ L. Moreira, ${ }^{7}$ R. Moreno, ${ }^{56}$

F. Moro ${ }^{89}$ A. W. Morris,${ }^{7}$ J. Morris,${ }^{7}$ L. Moser, ${ }^{26}$ S. Mosher, ${ }^{72}$ D. Moulton,,${ }^{7}$, A. Murari, ${ }^{12,35}$ A. Muraro, ${ }^{44}$ S. Murphy, ${ }^{7}$

N. N. Asakura, ${ }^{68}$ Y. S. Na, ${ }^{79}$ F. Nabais,${ }^{52}$ R. Naish, ${ }^{7}$ T. Nakano, ${ }^{68}$ E. Nardon, ${ }^{8}$ V. Naulin, ${ }^{82}$ M. F. F. Nave, ${ }^{52}$ I. Nedzelski, ${ }^{52}$

G. Nemtsev, ${ }^{87}$ F. Nespoli, ${ }^{33}$ A. Neto, ${ }^{40}$ R. Neu, ${ }^{61}$ V. S. Neverov, ${ }^{71}$ M. Newman, ${ }^{7}$ K. J. Nicholls, ${ }^{7}$ T. Nicolas, ${ }^{33}$ A. H. Nielsen, ${ }^{82}$ P. Nielsen, ${ }^{12}$ E. Nilsson, ${ }^{8}$ D. Nishijima, ${ }^{98}$ C. Noble,${ }^{7}$ M. Nocente, ${ }^{96}$ D. Nodwell, ${ }^{7}$ K. Nordlund, ${ }^{100}$ H. Nordman, ${ }^{16}$

R. Nouailletas, ${ }^{8}$ I. Nunes, ${ }^{52}$ M. Oberkofler, ${ }^{61}$ T. Odupitan, ${ }^{7}$ M. T. Ogawa, ${ }^{68}$ T. O' Gorman, ${ }^{7}$ M. Okabayashi, ${ }^{75}$ R. Olney, ${ }^{7}$ O. Omolayo, ${ }^{7}$ M. O'Mullane, ${ }^{21}$ J. Ongena, ${ }^{57}$ F. Orsitto, ${ }^{11}$ J. Orszagh, ${ }^{18}$ B. I. Oswuigwe, ${ }^{7}$ R. Otin, ${ }^{7}$ A. Owen, ${ }^{7}$ R. Paccagnella, ${ }^{12}$

N. Pace, ${ }^{7}$ D. Pacella, ${ }^{89}$ L. W. Packer, ${ }^{7}$ A. Page, ${ }^{7}$ E. Pajuste, ${ }^{102}$ S. Palazzo, ${ }^{30}$ S. Pamela, ${ }^{7}$ S. Panja ${ }^{45}$ P. Papp,${ }^{18}$ R. Paprok, ${ }^{49}$

V. Parail, ${ }^{7}$ M. Park, ${ }^{65}$ F. Parra Diaz, ${ }^{27}$ M. Parsons, ${ }^{72}$ R. Pasqualotto, ${ }^{12}$ A. Patel, ${ }^{7}$ S. Pathak,${ }^{45}$ D. Paton, ${ }^{7}$ H. Patten, ${ }^{33}$ A. Pau, ${ }^{17}$ E. Pawelec, ${ }^{47}$ C. Paz Soldan, ${ }^{42}$ A. Peackoc, ${ }^{36}$ I. J. Pearson, ${ }^{7}$ S.-P. Pehkonen, ${ }^{111}$ E. Peluso, ${ }^{94}$ C. Penot,${ }^{54}$ A. Pereira, ${ }^{56}$

R. Pereira, ${ }^{52}$ P. P. Pereira Puglia, ${ }^{7}$ C. Perez von Thun, ${ }^{35,38}$ S. Peruzzo, ${ }^{12}$ S. Peschanyi, ${ }^{55}$ M. Peterka, ${ }^{49}$ P. Petersson, ${ }^{41}$

G. Petravich, ${ }^{112}$ A. Petre,${ }^{83}$ N. Petrella,${ }^{7}$ V. Petrzilka, ${ }^{49}$ Y. Peysson, ${ }^{8}$ D. Pfefferlé, ${ }^{33}$ V. Philipps, ${ }^{38}$ M. Pillon, ${ }^{89}$ G. Pintsuk, ${ }^{38}$ P. Piovesan, ${ }^{12}$ A. Pires dos Reis,${ }^{51}$ L. Piron, ${ }^{7}$ A. Pironti, ${ }^{104}$ F. Pisano, ${ }^{17}$ R. Pitts, ${ }^{54}$ F. Pizzo, ${ }^{78}$ V. Plyusnin,${ }^{52}$ N. Pomaro, ${ }^{12}$ O. G. Pompilian, ${ }^{85}$ P. J. Pool, ${ }^{7}$ S. Popovichev, ${ }^{7}$ M. T. Porfiri,${ }^{89}$ C. Porosnicu, ${ }^{85}$ M. Porton, ${ }^{7}$ G. Possnert, ${ }^{22}$ S. Potzel, ${ }^{61}$ T. Powell, ${ }^{7}$ J. Pozzi, ${ }^{7}$ V. Prajapati, ${ }^{45}$ R. Prakash, ${ }^{45}$ G. Prestopino, ${ }^{94}$ D. Price, ${ }^{7}$ M. Price, ${ }^{7}$ R. Price, ${ }^{7}$ P. Prior, ${ }^{7}$ R. Proudfoot, ${ }^{7}$ G. Pucella, ${ }^{89}$ P. Puglia, ${ }^{51}$ M. E. Puiatti, ${ }^{12}$ D. Pulley, ${ }^{7}$ K. Purahoo, ${ }^{7}$ Th. Pütterich, ${ }^{61}$ E. Rachlew, ${ }^{25}$ M. Rack, ${ }^{38}$ R. Ragona ${ }^{57}$ M. S. J. Rainford, ${ }^{7}$ A. Rakha, ${ }^{6}$ G. Ramogida, ${ }^{89}$ S. Ranjan, ${ }^{45}$ C. J. Rapson, ${ }^{61}$ J. J. Rasmussen, ${ }^{82}$ K. Rathod, ${ }^{45}$ G. Rattà ${ }^{56}$ S. Ratynskaia, ${ }^{81}$ G. Ravera, ${ }^{89}$ C. Rayner, ${ }^{7}$ M. Rebai, ${ }^{96}$ D. Reece, ${ }^{7}$ A. Reed, ${ }^{7}$ D. Réfy, ${ }^{112}$ B. Regan, ${ }^{7}$ J. Regana, ${ }^{34}$ M. Reich, ${ }^{61}$ N. Reid, ${ }^{7}$ F. Reimold, ${ }^{38}$ M. Reinhart, ${ }^{34}$ M. Reinke, ${ }^{109,72}$ D. Reiser, ${ }^{38}$ D. Rendell, ${ }^{7}$ C. Reux, ${ }^{8}$ S. D. A. Reyes Cortes, ${ }^{52}$ 
S. Reynolds, ${ }^{7}$ V. Riccardo, ${ }^{7}$ N. Richardson, ${ }^{7}$ K. Riddle, ${ }^{7}$ D. Rigamonti, ${ }^{96}$ F. G. Rimini, ${ }^{7}$ J. Risner, ${ }^{72}$ M. Riva, ${ }^{89}$ C. Roach, ${ }^{7}$ R. J. Robins, ${ }^{7}$ S. A. Robinson, ${ }^{7}$ T. Robinson, ${ }^{7}$ D. W. Robson, ${ }^{7}$ R. Roccella, ${ }^{54}$ R. Rodionov,${ }^{87}$ P. Rodrigues, ${ }^{52}$ J. Rodriguez, ${ }^{7}$ V. Rohde, ${ }^{61}$ F. Romanelli, ${ }^{89}$ M. Romanelli, ${ }^{7}$ S. Romanelli, ${ }^{7}$ J. Romazanov, ${ }^{38}$ S. Rowe ${ }^{7}$ M. Rubel, ${ }^{41}$ G. Rubinacci, ${ }^{104}$ G. Rubino, ${ }^{12}$ L. Ruchko, ${ }^{51}$ M. Ruiz, ${ }^{93}$ C. Ruset, ${ }^{85}$ J. Rzadkiewicz, ${ }^{64}$ S. Saarelma, ${ }^{7}$ R. Sabot,${ }^{8}$ E. Safi, ${ }^{100}$ P. Sagar, ${ }^{7}$ G. Saibene, ${ }^{40}$ F. Saint-Laurent, ${ }^{8}$ M. Salewski, ${ }^{82}$ A. Salmi, ${ }^{111}$ R. Salmon, ${ }^{7}$ F. Salzedas, ${ }^{52}$ D. Samaddar, ${ }^{7}$ U. Samm, ${ }^{38}$ D. Sandiford, ${ }^{7}$ P. Santa, ${ }^{45}$ M. I. K. Santala, ${ }^{1}$ B. Santos, ${ }^{52}$ A. Santucci, ${ }^{89}$ F. Sartori, ${ }^{40}$ R. Sartori, ${ }^{40}$ O. Sauter, ${ }^{33}$ R. Scannell, ${ }^{7}$ T. Schlummer, ${ }^{38}$ K. Schmid, ${ }^{61}$ V. Schmidt, ${ }^{12}$ S. Schmuck, ${ }^{7}$ M. Schneider, ${ }^{8}$ K. Schöpf, ${ }^{101}$ D. Schwörer, ${ }^{32}$ S. D. Scott, ${ }^{75}$ G. Sergienko, ${ }^{38}$ M. Sertoli, ${ }^{61}$ A. Shabbir, ${ }^{15}$ S. E. Sharapov, ${ }^{7}$ A. Shaw, ${ }^{7}$ R. Shaw, ${ }^{7}$ H. Sheikh, ${ }^{7}$ A. Shepherd, ${ }^{7}$ A. Shevelev, ${ }^{53}$ A. Shumack, ${ }^{37}$ G. Sias, ${ }^{17}$ M. Sibbald, ${ }^{7}$ B. Sieglin, ${ }^{61}$ S. Silburn, ${ }^{7}$ A. Silva, ${ }^{52}$ C. Silva, ${ }^{52}$ P. A. Simmons, ${ }^{7}$ J. Simpson, ${ }^{7}$ J. Simpson-Hutchinson, ${ }^{7}$ A. Sinha, ${ }^{45}$ S. K. Sipilä, ${ }^{1}$ A. C. C. Sips ${ }^{36}$ P. Sirén, ${ }^{111}$ A. Sirinelli, ${ }^{54}$ H. Sjöstrand, ${ }^{22}$ M. Skiba, ${ }^{22}$ R. Skilton, ${ }^{7}$ K. Slabkowska, ${ }^{48}$ B. Slade, ${ }^{7}$ N. Smith, ${ }^{7}$ P. G. Smith, ${ }^{7}$ R. Smith, ${ }^{7}$ T. J. Smith, ${ }^{7}$ M. Smithies, ${ }^{109}$ L. Snoj,${ }^{80}$ S. Soare, ${ }^{84}$ E. R. Solano, ${ }^{35,56}$ A. Somers, ${ }^{32}$ C. Sommariva, ${ }^{8}$ P. Sonato, ${ }^{12}$ A. Sopplesa, ${ }^{12}$ J. Sousa, ${ }^{52}$ C. Sozzi, ${ }^{44}$ S. Spagnolo, ${ }^{12}$ T. Spelzini, ${ }^{7}$ F. Spineanu, ${ }^{85}$ G. Stables, ${ }^{7}$ I. Stamatelatos, ${ }^{70}$ M. F. Stamp, ${ }^{7}$ P. Staniec, ${ }^{7}$ G. Stankunas, ${ }^{58}$ C. Stan-Sion, ${ }^{83}$ M. J. Stead ${ }^{7}$ E. Stefanikova, ${ }^{41}$ I. Stepanov, ${ }^{57}$ A. V. Stephen, ${ }^{7}$ M. Stephen, ${ }^{45}$ A. Stevens, ${ }^{7}$ B. D. Stevens, ${ }^{7}$ J. Strachan, ${ }^{75}$ P. Strand, ${ }^{16}$ H. R. Strauss, ${ }^{43}$ P. Ström, ${ }^{41}$ G. Stubbs, ${ }^{7}$ W. Studholme, ${ }^{7}$ F. Subba, ${ }^{74}$ H. P. Summers, ${ }^{21}$ J. Svensson, ${ }^{62}$ L. Swiderski, ${ }^{64}$ T. Szabolics, ${ }^{112}$ M. Szawlowski, ${ }^{48}$ G. Szepesi, ${ }^{7}$ T. T. Suzuki, ${ }^{68}$ B. Tàl, ${ }^{112}$ T. Tala, ${ }^{111}$ A. R. Talbot, ${ }^{7}$ S. Talebzadeh,${ }^{94}$ C. Taliercio, ${ }^{12}$ P. Tamain,${ }^{8}$ C. Tame, ${ }^{7}$

W. Tang ${ }^{75}$ M. Tardocchi, ${ }^{44}$ L. Taroni, ${ }^{12}$ D. Taylor, ${ }^{7}$ K. A. Taylor, ${ }^{7}$ D. Tegnered, ${ }^{16}$ G. Telesca, ${ }^{15}$ N. Teplova, ${ }^{53}$ D. Terranova, ${ }^{12}$ D. Testa, ${ }^{33}$ E. Tholerus, ${ }^{41}$ J. Thomas, ${ }^{7}$ J. D. Thomas, ${ }^{7}$ P. Thomas, ${ }^{54}$ A. Thompson, ${ }^{7}$ C.-A. Thompson, ${ }^{7}$ V. K. Thompson, ${ }^{7}$ L. Thorne, ${ }^{7}$ A. Thornton, ${ }^{7}$ A. S. Thrysoe, ${ }^{82}$ P. A. Tigwell, ${ }^{7}$ N. Tipton, ${ }^{7}$ I. Tiseanu, ${ }^{85}$ H. Tojo, ${ }^{68}$ M. Tokitani, ${ }^{66}$ P. Tolias,${ }^{81}$ M. Tomes ${ }^{49}$ P. Tonner, ${ }^{7}$ M. Towndrow, ${ }^{7}$ P. Trimble,${ }^{7}$ M. Tripsky, ${ }^{57}$ M. Tsalas,${ }^{37}$ P. Tsavalas,${ }^{70}$ D. Tskhakaya jun, ${ }^{101}$ I. Turner, ${ }^{7}$ M. M. Turner, ${ }^{32}$ M. Turnyanskiy, ${ }^{34}$ G. Tvalashvili, ${ }^{7}$ S. G. J. Tyrrell, ${ }^{7}$ A. Uccello, ${ }^{44}$ Z. Ul-Abidin, ${ }^{7}$ J. Uljanovs, ${ }^{1}$ D. Ulyatt, ${ }^{7}$ H. Urano, ${ }^{68}$ I. Uytdenhouwen, ${ }^{77}$ A. P. Vadgama, ${ }^{7}$ D. Valcarcel, ${ }^{7}$ M. Valentinuzzi, ${ }^{8}$ M. Valisa, ${ }^{12}$ P. Vallejos Olivares, ${ }^{41}$ M. Valovic, ${ }^{7}$ M. Van De Mortel, ${ }^{7}$ D. Van Eester, ${ }^{57}$ W. Van Renterghem, ${ }^{77}$ G. J. van Rooij, ${ }^{37}$ J. Varje, ${ }^{1}$ S. Varoutis, ${ }^{55}$ S. Vartanian, ${ }^{8}$ K. Vasava ${ }^{45}$ T. Vasilopoulou, ${ }^{70}$ J. Vega, ${ }^{56}$ G. Verdoolaege,${ }^{57}$ R. Verhoeven, ${ }^{7}$ C. Verona, ${ }^{94}$ G. Verona Rinati, ${ }^{94}$ E. Veshchev,${ }^{54}$ N. Vianello, ${ }^{44}$ J. Vicente, ${ }^{52}$ E. Viezzer, ${ }^{61,91}$ S. Villari, ${ }^{89}$ F. Villone, ${ }^{99}$ P. Vincenzi, ${ }^{12}$ I. Vinyar, ${ }^{73}$ B. Viola, ${ }^{89}$ A. Vitins, ${ }^{102}$ Z. Vizvary, ${ }^{7}$ M. Vlad,${ }^{85}$ I. Voitsekhovitch,${ }^{34}$ P. Vondràcek,${ }^{49}$ N. Vora, ${ }^{7}$ T. Vu, ${ }^{8}$ W. W. Pires de Sa, ${ }^{51}$ B. Wakeling, ${ }^{7}$ C. W. F. Waldon, ${ }^{7}$ N. Walkden, ${ }^{7}$ M. Walker, ${ }^{7}$ R. Walker, ${ }^{7}$ M. Walsh,${ }^{54}$ E. Wang, ${ }^{38}$ N. Wang, ${ }^{38}$ S. Warder, ${ }^{7}$ R. J. Warren, ${ }^{7}$ J. Waterhouse, ${ }^{7}$ N. W. Watkins, ${ }^{28}$ C. Watts, ${ }^{54}$ T. Wauters, ${ }^{57}$ A. Weckmann, ${ }^{41}$ J. Weiland, ${ }^{23}$ H. Weisen, ${ }^{33}$ M. Weiszflog, ${ }^{22}$

C. Wellstood, ${ }^{7}$ A. T. West, ${ }^{7}$ M. R. Wheatley, ${ }^{7}$ S. Whetham, ${ }^{7}$ A. M. Whitehead, ${ }^{7}$ B. D. Whitehead, ${ }^{7}$ A. M. Widdowson, ${ }^{7}$

S. Wiesen, ${ }^{38}$ J. Wilkinson, ${ }^{7}$ J. Williams, ${ }^{7}$ M. Williams, ${ }^{7}$ A. R. Wilson, ${ }^{7}$ D. J. Wilson, ${ }^{7}$ H. R. Wilson, ${ }^{109}$ J. Wilson, ${ }^{7}$

M. Wischmeier, ${ }^{61}$ G. Withenshaw, ${ }^{7}$ A. Withycombe, ${ }^{7}$ D. M. Witts, ${ }^{7}$ D. Wood, ${ }^{7}$ R. Wood, ${ }^{7}$ C. Woodley, ${ }^{7}$ S. Wray, ${ }^{7}$ J. Wright, ${ }^{7}$ J. C. Wright, ${ }^{63}$ J. Wu, ${ }^{88}$ S. Wukitch, ${ }^{63}$ A. Wynn, ${ }^{109}$ T. Xu, ${ }^{7}$ D. Yadikin, ${ }^{16}$ W. Yanling, ${ }^{38}$ L. Yao, ${ }^{88}$ V. Yavorskij, ${ }^{101}$ M. G. Yoo, ${ }^{79}$ C. Young, ${ }^{7}$ D. Young, ${ }^{7}$ I. D. Young, ${ }^{7}$ R. Young, ${ }^{7}$ J. Zacks, ${ }^{7}$ R. Zagorski,${ }^{48}$ F. S. Zaitsev, ${ }^{18}$ R. Zanino, ${ }^{74}$ A. Zarins, ${ }^{102}$

K. D. Zastrow, ${ }^{7}$ M. Zerbini, ${ }^{89}$ W. Zhang, ${ }^{61}$ Y. Zhou, ${ }^{41}$ E. Zilli, ${ }^{12}$ V. Zoita, ${ }^{85}$ S. Zoletnik, ${ }^{112}$ and I. Zychor ${ }^{64}$

${ }^{1}$ Aalto University, P.O. Box 14100, FIN-00076 Aalto, Finland

${ }^{2}$ Aix Marseille Université, CNRS, Centrale Marseille, M2P2 UMR 7339, 13451, Marseille, France

${ }^{3}$ Aix-Marseille Université, CNRS, IUSTI UMR 7344, 13013 Marseille, France

${ }^{4}$ Aix-Marseille Université, CNRS, PIIM, UMR 7345, 13013 Marseille, France

${ }^{5}$ Arizona State University, Tempe, Arizona, USA

${ }^{6}$ Barcelona Supercomputing Center, Barcelona, Spain

${ }^{7}$ CCFE, Culham Science Centre, Abingdon, Oxon, OX14 3DB, United Kingdom

${ }^{8}$ CEA, IRFM, F-13108 Saint Paul Lez Durance, France

${ }^{9}$ Center for Energy Research, University of California at San Diego, La Jolla, California 92093, USA

${ }^{10}$ Centro Brasileiro de Pesquisas Fisicas, Rua Xavier Sigaud, 160, Rio de Janeiro CEP 22290-180, Brazil

${ }^{11}$ Consorzio CREATE, Via Claudio 21, 80125 Napoli, Italy

${ }^{12}$ Consorzio RFX, corso Stati Uniti 4, 35127 Padova, Italy

${ }^{13}$ Daegu University, Jillyang, Gyeongsan, Gyeongbuk 712-174, Republic of Korea

${ }^{14}$ Departamento de Física, Universidad Carlos III de Madrid, 28911 Leganés, Madrid, Spain

${ }^{15}$ Department of Applied Physics UG (Ghent University) St-Pietersnieuwstraat 41 B-9000 Ghent, Belgium

${ }^{16}$ Department of Earth and Space Sciences, Chalmers University of Technology, SE-41296 Gothenburg, Sweden

${ }^{17}$ Department of Electrical and Electronic Engineering, University of Cagliari, Piazza d'Armi 09123 Cagliari, Italy

${ }^{18}$ Department of Experimental Physics, Faculty of Mathematics, Physics and Informatics Comenius University Mlynska dolina F2, 84248 Bratislava, Slovakia

${ }^{19}$ Department of Materials Science, Warsaw University of Technology, PL-01-152 Warsaw, Poland

${ }^{20}$ Department of Nuclear and Quantum Engineering, KAIST, Daejeon 34141, Korea

${ }^{21}$ Department of Physics and Applied Physics, University of Strathclyde, Glasgow, G4 ONG, United Kingdom

${ }^{22}$ Department of Physics and Astronomy, Uppsala University, SE-75120 Uppsala, Sweden

${ }^{23}$ Department of Physics, Chalmers University of Technology, SE-41296 Gothenburg, Sweden

${ }^{24}$ Department of Physics, Imperial College London, London, SW7 2AZ, United Kingdom 


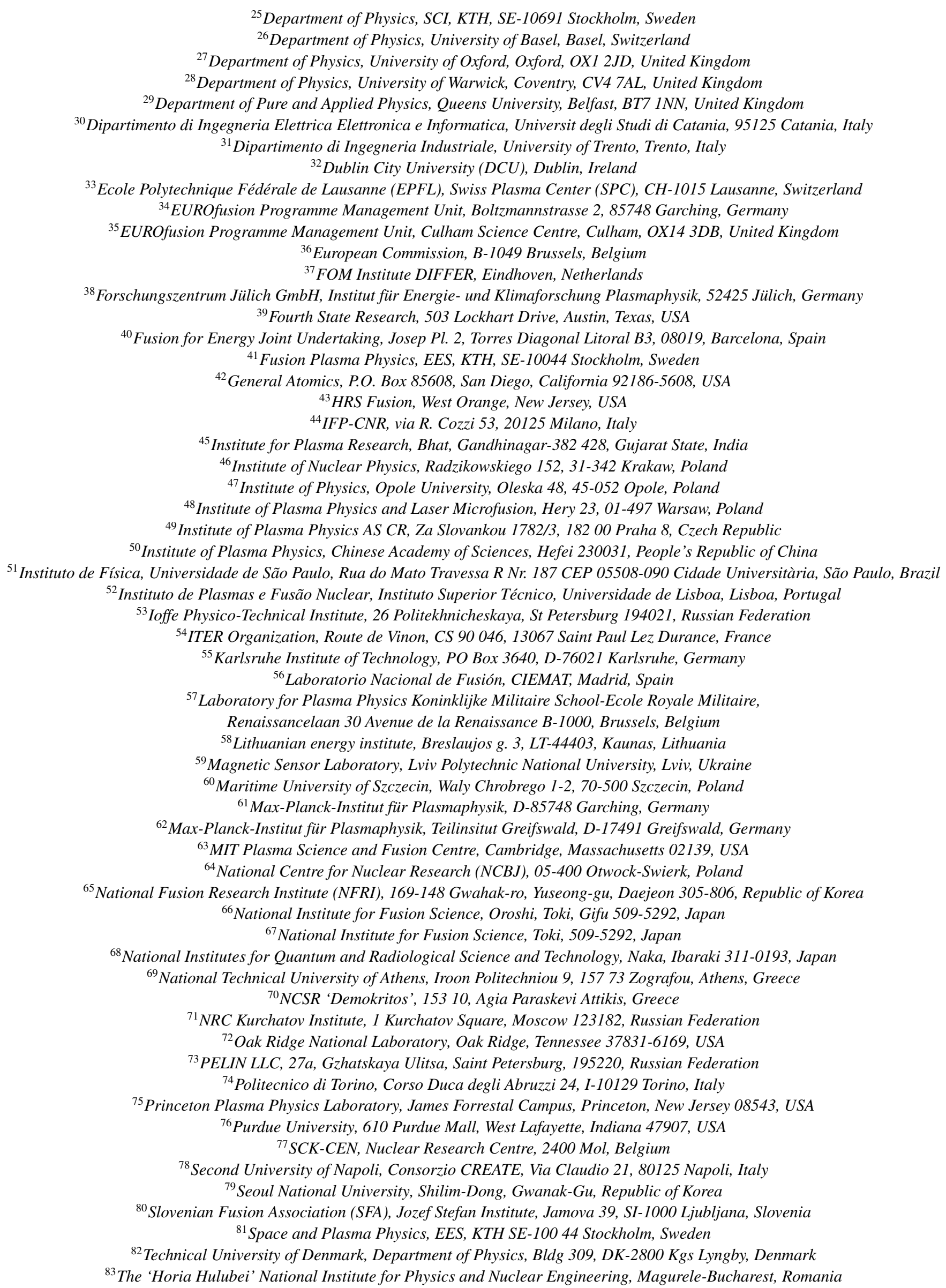


${ }^{84}$ The National Institute for Cryogenics and Isotopic Technology, Ramnicu Valcea, Romania

${ }^{85}$ The National Institute for Laser, Plasma, and Radiation Physics, Magurele-Bucharest, Romania

${ }^{86}$ The National Institute for Optoelectronics, Magurele-Bucharest, Romania

${ }^{87}$ Troitsk Insitute of Innovating and Thermonuclear Research (TRINITI), Troitsk 142190, Moscow Region, Russian Federation

${ }^{88}$ University of Electronic Science and Technology of China, Chengdu, People's Republic of China

${ }^{89}$ Unità Tecnica Fusione, ENEA C. R. Frascati, via E. Fermi 45, 00044 Frascati (Roma), Italy

${ }^{90}$ Universidad Complutense de Madrid, Madrid, Spain

${ }^{91}$ Universidad de Sevilla, Sevilla, Spain

${ }^{92}$ Universidad Nacional de Educaciòn a Distancia, Madrid, Spain

${ }^{93}$ Universidad Politécnica de Madrid, Grupo I2A2, Madrid, Spain

${ }^{94}$ Università di Roma Tor Vergata, Via del Politecnico 1, Roma, Italy

${ }^{95}$ University College Cork (UCC), Ireland

${ }^{96}$ University Milano-Bicocca, piazza della Scienza 3, 20126 Milano, Italy

${ }^{97}$ University of Basilicata, Consorzio CREATE, Via Claudio 21, 80125 Napoli, Italy

${ }^{98}$ University of California, 1111 Franklin Street, Oakland, California 94607, USA

${ }^{99}$ University of Cassino, Consorzio CREATE, Via Claudio 21, 80125 Napoli, Italy

${ }^{100}$ University of Helsinki, P.O. Box 43, FI-00014 University of Helsinki, Finland

${ }^{101}$ University of Innsbruck, Fusion@ Osterreichische Akademie der Wissenschaften (ÖAW), Innsbruck, Austria

${ }^{102}$ University of Latvia, 19 Raina Boulevard, Riga, LV 1586, Latvia

${ }^{103}$ University of Lorraine, CNRS, UMR7198, YIJL, Nancy, France

${ }^{104}$ University of Napoli 'Federico II', Consorzio CREATE, Via Claudio 21, 80125 Napoli, Italy

${ }^{105}$ University of Napoli Parthenope, Consorzio CREATE, Via Claudio 21, 80125 Napoli, Italy

${ }^{106}$ University of Texas at Austin, Institute for Fusion Studies, Austin, Texas 78712, USA

${ }^{107}$ University of Toyama, Toyama, 930-8555, Japan

${ }^{108}$ University of Tuscia, DEIM, Via del Paradiso 47, 01100 Viterbo, Italy

${ }^{109}$ University of York, Heslington, York YO10 5DD, United Kingdom

${ }^{110}$ Vienna University of Technology, Fusion@ Osterreichische Akademie der Wissenschaften (ÖAW), Austria

${ }^{111}$ VTT Technical Research Centre of Finland, P.O. Box 1000, FIN-02044 VTT, Finland

${ }^{112}$ Wigner Research Centre for Physics, P.O. Box 49, H-1525 Budapest, Hungary 